\title{
CONVENIENT APPROXIMATION TECHNIQUES FOR STORM AND FLOOD DISASTER RISK FINANCE IN THE RAILWAY BUSINESS
}

\author{
Katsumasa OHORI ${ }^{1}$ \\ ${ }^{1}$ Member of JSCE, Associate Professor, Iwate Prefectural University \\ (152-52, Sugo, Takizawa, Iwate 020-0693, Japan) \\ E-mail: katsu_o@iwate-pu.ac.jp
}

\begin{abstract}
The storm and flood disasters account for $90 \%$ of the disasters that have led to the abolishment of railways in Japan. Such disasters are an overwhelming risk factor for many railway businesses in this country. Because the numbers of storm and flooding disasters have increased and intensified globally due to climate change, the importance of storm and flooding disaster risk financing (RF) has increased in many railway businesses. In this context, based on the Cramér-Lundberg model of disaster characteristics and financial conditions, this study proposes convenient approximation techniques to determine ruin probability and additional procurable funds, which are vital in storm and flooding disaster RF. Specifically, we present six theoretical approximation formulas of ruin probability and additional procurable funds, which meet the technical requirements (i.e., conservativeness, approximation accuracies, and domain) for practical work in $\mathrm{RF}$. The technical requirements of these theoretical approximation formulas are evaluated using actual data collected in railway companies across Japan. The convenient usage of these formulas is also evaluated.
\end{abstract}

Key Words : railway, natural disaster, risk finance, ruin probability, approximation theory

\section{INTRODUCTION}

In Japan, people's lives and property are lost yearly because of natural disasters, such as typhoons, torrential rains, heavy snowfall, earthquakes, and tsunamis. As many as 30 railways in Japan have been abolished because of the damage caused by a natural disaster. In the period FY1950-2014, an annual average of 0.45 railways were shut down because of the damage caused by natural disasters ${ }^{1)-3 \text {. }}$.

The procurement of natural disaster recovery funds that require a huge one-time payment is a critical issue for the survival of companies that have huge railway structures. If railway companies are severely affected by natural disasters and are unable to procure recovery funds, then bankruptcy or the closure of the business is inevitable, which results in a significant negative effect on the economies of the communities along the railway lines. To avoid such situations, it is necessary to implement financial measures that are called risk financing (RF). Although natural disaster $\mathrm{RF}$ is important not only for railway companies but also for the local residents concerned, its implementation remains low $^{3)-6}$. Many railway businesses in Japan are private companies that are financially independent. Moreover, it has been reported that they find it difficult to procure natural disaster recovery funds because of problems in public financial support, insurance, and other sources ${ }^{1)-6)}$.

Storms and flooding account for $90 \%$ of the natural disasters that have led to the abolishment of railways in Japan. 92\% of the abolished railways have affected third-sector railway companies. Hence, storms and flooding pose overwhelming risks factor for railway businesses ${ }^{1-3)}$. Because climate change has led to an increase in storms and flooding ${ }^{7)-10)}$, the damage to railways caused by these natural disasters has also increased and intensified ${ }^{11), 12)}$, which has led to increases in the premiums paid to insure civil engineer-

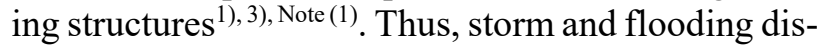
aster RF has become vital for railway businesses in financial difficulty (e.g., small- and medium-sized private railway companies, third- sector railway companies).

In their examination of this issue, Ohori and Morichi $(2016)^{2)}$ verified the probability distribution of losses caused by storm and flooding disasters. Based on their statistical results, they proposed the ruin probability of a railway business, which has been significant in mathematical analyses of storm and flooding disaster RF. 
This study proposes convenient techniques for approximating ruin probability and additional procurable funds. These techniques are of great interest for practical RF based on the Cramér-Lundberg model ${ }^{15)-22)}$. In the proposed mathematical model of storm and flooding disaster RF, the differences in the characteristics and financial conditions of each railway business must be considered. Specifically, we present several theoretical formulas to approximate ruin probability and additional procurable funding. These formulas are convenient, and they meet essential technical requirements (i.e., conservativeness, approximate accuracy, and domain) for practical work in RF. Moreover, the technical requirements of the approximation theory are evaluated through an evaluation using actual data that were collected across Japan. We then propose convenient approximation techniques that are useful for practical applications in RF.

Figure 1 shows the different chapters of this study. Section 2 describes the relationship of this study to previous relevant studies in the literature. Section 3 presents two propositions (Proposition 1 and 2), which play key roles in the conservative approximation of ruin probability and additional procurable funds in a ruin probability model of storm and flooding disaster RF by taking into account the proposal by Ohori and Morichi $(2016)^{2)}$. Section 4 describes the adjustment coefficient that constitutes ruin probability and additional procurable funds and proposes theoretical formulas for the conservative approximation of ruin probability and additional procurable funds based on the three ideas mentioned. In Section $\mathbf{5}$, by using real data on storm and flooding disasters and the financial conditions of railway companies across Japan, the approximation techniques for determining ruin probability and additional procurable funds in Section $\mathbf{4}$ are evaluated, and the technical requirements (i.e., conservativeness, domain, and approximate accuracy) are verified. Moreover, the convenient usage of these techniques is evaluated. Section 6 summarizes the main results and further work for both theory and practice.

\section{FUNDAMENTAL VIEWPOINT}

\section{(1) Previous studies on natural disaster RF}

In Japan, regarding natural disaster RF for transport infrastructure, including railways, airports, and ports, Uchida et al. (2009) ${ }^{4}$ conducted a questionnaire survey of all transport business operators to determine the status and issues of the company. Based on their findings, Morichi $(2009)^{5)}$ recommended that the national government establish a subsidy system for disaster restoration and insurance.

\begin{tabular}{|l|}
\hline 1. Introduction \\
\hline 2. Fundamental Viewpoint \\
\hline Convenient Approximation Techniques \\
\hline 3. Mathmatical Model and the Core Approximation Theory \\
\hline 4. Approximation Techniques \\
\hline 5. Evaluation of Approximation Techniques \\
\hline \\
\hline
\end{tabular}

Fig. 1 Chapter constitution of this study.

Based on the results of a survey by Uchida et al. $(2009)^{4)}$ and the status of natural disaster RF determined by Shikoku Railway Company, Morichi $(2009)^{5)}$ and Nozawa et al. $(2010)^{6)}$ pointed to the inadequacy of natural disaster insurance for civil engineering structures, as well as the subsidy system for disaster restoration under the Act on Improvement of Railroads and Rail Tracks. In addition, Ohori (2015, 2016) ${ }^{1)-3)}$ clarified the following characteristics of natural disaster RF based on interviews ${ }^{\text {Note (1) }}$.

a) Natural disaster RF differs between major railway businesses and small- and medium-sized railway businesses. The differences are described in b) and c) below.

b) Well-managed major private railway companies anticipate a probable maximum loss (PML) caused by earthquakes or tsunamis in many cases $^{7)-14)}$. Their risk-treatment measures include the active implementation of risk control, such as seismic strengthening, and advanced RF, such as earthquake insurance and alternative risk transfer $(\mathrm{ART})^{14)}$.

c) The primary concerns of railway businesses in financial difficulty (i.e., small and medium-sized private railway companies and third-sector railway companies) are the storm and flooding disasters that occur frequently. Many experts have pointed out that RF for potential earthquakes and tsunamis is difficult and that such railway companies entirely depend on public financial support.

d) While they struggle to improve the bottom line of annual financial statements or maintain a cash flow, railway businesses in financial difficulty hope to mitigate the burden of insurance premiums. They also have strong requirements for short-term, effective RF to avoid a cash shortage during the recovery from a disaster.

Based on the real situations described above, Ohori and Morichi (2016) ${ }^{2)}$ analyzed data collected from railway businesses. Their results are summarized as follows: 
a) The major elements of RF, that is, disaster characteristics and financial conditions, differ greatly among railway businesses.

b) Regarding storm and flooding disasters, it is statistically proven that the number of losses in a fixed time interval conforms to the Poisson distribution, and the amount of loss per disaster conforms to the exponential distribution.

c) A ruin probability model of a railway business in cases of storm and flooding disasters based on the Cramér-Lundberg model is proposed.

(2) Need for approximation techniques for storm and flooding disaster $R F$ in railway businesses

Regarding storm and flooding disaster RF in railway businesses, the procurement of financing for disaster restoration varies widely depending on the characteristics of the disaster and the financial conditions. Thus, when storm and flooding disasters occur, railway companies are required to obtain a necessary amount of money to ensure the stability of their corporate management. However, they must determine their financial position before applying for RF, including the conclusion of insurance contracts.

However, in Japan, many railway businesses are in a severe management situation, and they have little expertise in RF. Moreover, the outsourcing of storm and flooding disaster RF is difficult because of their financial resources. Therefore, convenient approximation techniques are desired to reduce the required technical calculations related to storm and flooding disaster $\mathrm{RF}^{\text {Note }(1)}$.

In many cases, in storm and flooding disaster RF of railway businesses, insurance contract conditions are examined, including maximum insurance payments, which can amount to hundreds of millions of yen based on the ability to pay. Internal reserves and cash reserves, such as funds in preparation for disasters, are given ${ }^{\text {Note }(1)}$. In other words, based on the ruin probability model presented by Ohori and Morichi $(2016)^{2)}$, in storm and flooding disaster RF in railway business, of greatest importance are ruin probability and additional procurable funds. Hence, the practical ability to obtain RF would be greatly improved if it were possible to analyze these two items.

In practical RF, three broad technical requirements are necessary for approximation. The first requirement is a conservative (higher) approximation to avoid the shortage of disaster restoration funds. The second requirement is to pay attention to the domain in consideration of convergence in the approximation calculation. The third requirement is to ensure a practically allowable accuracy of the approximation. For example, it should be noted that a theoretical domain cannot be applied in practice if the approximation is not accurate, which could cause a difference of more than billions of yen.

\section{(3) Previous studies on approximation techniques for ruin probability}

In the finance and insurance fields, risk theory or ruin theory, is used to deal with bankruptcy problems following huge losses, such as those caused by the Great Depression or catastrophic natural disasters. The theoretical foundation of risk theory, which is known as the Cramér-Lundberg model, was introduced in 1903 by Filip Lundberg ${ }^{15)}$. Lundberg's work was republished in the 1930s by Harald Cramér ${ }^{16),}$ 17). Since then, risk theory has been developed for use in mathematical analysis ${ }^{19)-22)}$.

In general, it is exceedingly difficult to derive explicit and closed expressions for ruin probability. However, under suitable conditions, some approximations of ruin probability can be obtained. Pioneering works on approximations of ruin probability were obtained using the framework of the Cramér Lundberg model ${ }^{15-17)}$ and by Sparre Andersen $(1957)^{18)}$. In risk theory, Lundberg's inequality is a well-known convenient theorem for conservatively estimating ruin probability ${ }^{19)-22}$. Lundberg's inequality is summarized in Section 3.(4). To the extent that Lundberg's inequality is employed, a conservative approximation value of ruin probability can be obtained by using the adjustment coefficient as described in Section 3.(4) below. In previous studies $^{19)-22)}$, an asymptotic approximation based on the Newton-Raphson method is frequently recommended as a method for calculating the adjustment coefficient. In this case, initial values are often determined up to the quadratic term by the Maclaurin expansion.

However, as far as the author knows, there is no systematic approximation theory of technical requirements, such as the approximation domain and the accuracy of the approximation of ruin probability of storm and flooding disaster RF in the railway business. In addition, to the best of the author's knowledge, no evaluation of the data of actual disasters and financial results in the railway business based on approximation theory has been derived. Therefore, no practical approximation technique to determine ruin probability and additional procurable funds in storm and flooding disaster RF in the railway business exists.

\section{(4) Fundamental viewpoint of this study}

In cases of storm and flooding disaster RF in the railway business, it is necessary to use multiple financing methods, including the utilization of cash reserves, insurance, and so on. The evaluation method is necessary in considering the disaster characteristics and financial conditions of each railway business. 
However, to the best of the author's knowledge, a systematic and clear theoretical basis for applying this scientific method can be found only in Ohori and Morichi $(2016)^{2)}$. Accordingly, in this study, we decided to consider storm and flooding disaster RF based on Ohori and Morichi's (2016) ${ }^{2)}$ framework, which is considered useful in terms of both theory and practice in estimating and examining fund procurement, including cash reserves in the following fiscal year or later, as well as insurance contract conditions. In our study, mathematical statistics and data analyses are based on this framework.

In addition, as described in Section 2.(2), convenient approximation techniques that meet the technical requirements of ruin probability and additional procurable funds are desired in the RF of storm and flooding disasters. Therefore, with reference to the previous studies reviewed in Section 2.(3), in order to consider approximation techniques as broadly as possible, the three ideas described in Section 4.(1) below are compared and examined. Finally, both the technical requirements (conservativeness, approximate accuracy, and domain) and convenience are inspected through evaluations of the proposed approximation techniques, which are intended for the practical application to RF.

\section{MATHEMATICAL MODEL AND THE CORE APPROXIMATION THEORY}

\section{(1) Model of aggregate loss caused by natural dis- asters}

Suppose that the random variable $S_{t}$ is an aggregate loss caused by natural disasters that occur in a fixed time interval $[0, t](t \geq 0)$ typically of one year based on the definitions in Ohori and Morichi $(2016)^{2)}$ within the framework of the Cramér-Lundberg model. The random variable $N_{t}$ represents the number of losses caused by natural disasters that occur in a fixed time interval $[0, t](t \geq 0)$, and the random variable $X_{i}$ represents the amount of loss caused by the $i$ th natural disaster $\left(i=1,2, \ldots, N_{t}\right)$.

We now consider two assumptions. First, $\left\{X_{i} ; i=\right.$ $1,2, \ldots\}$ is assumed to be a sequence of independent and identically distributed random variables. Second, the random variable $N_{t}$ is assumed to be independent of $\left\{X_{i} i=1,2, \ldots\right\}$.

Based on the two assumptions, the aggregate loss is the sum of individual loss amounts with the understanding that $S_{t}=0$ when $N_{t}=0$ as shown below:

$$
S_{t}=X_{1}+X_{2}+\cdots+X_{N_{t}} \text {. }
$$

(2) Aggregate loss caused by storm and flooding disasters in the railway business

In this section, we consider that storms and flooding are natural disasters. According to Ohori and Morichi $(2016)^{2)}$, the distribution of the number of losses caused by storm and flooding disasters that occur in a year conforms to the Poisson distribution, and the amount of each loss is exponentially distributed. Based on these findings, we express the aggregate loss caused by storm and flooding disasters that occur in a fixed time interval in the railway business as follows:

a) Annual number of losses caused by storm and flooding disasters in railway business

The random variable $N$ represents the number of losses caused by storm and flooding disasters that occur in a year, which conforms to the Poisson distribution with parameter $\lambda$, the probability function of which is given by the following formula:

$$
P(N=n)=e^{-\lambda} \frac{\lambda^{n}}{n !} \quad(n=0,1,2, \ldots) .
$$

Hence, the mean and variance are given by the following formula:

$$
E(N)=V(N)=\lambda .
$$

b) Amount of each loss caused by storm and flooding disasters in the railway business

The random variable $X$ represents the amount of each loss caused by a storm and flooding disaster. The random variable $X$ is exponentially distributed by parameter $\mu$, the density function of which is given by the following formula:

$$
f_{X}(x)=\frac{1}{\mu} \exp \left(-\frac{1}{\mu} x\right) \quad(x \geq 0) .
$$

The moment-generating function of $X$ is as follows:

$$
M_{X}(r)=\frac{1}{1-\mu r} \quad(|\mu r|<1) .
$$

Hence, it follows that

$$
\begin{gathered}
E(X)=M_{X}^{(1)}(0)=\mu \\
E\left(X^{k}\right)=M_{X}^{(k)}(0)=k ! \mu^{k} .
\end{gathered}
$$

c) Annual aggregate loss caused by storm and flooding disasters in the railway business

The random variable $S$ is calculated using the conditional expectation arguments as follows:

$$
\begin{gathered}
E(S)=\lambda \mu \\
V(S)=2 \lambda \mu^{2} \\
M_{S}(r)=M_{N}\left[\log M_{X}(r)\right]=\exp \left(\frac{\lambda \mu r}{1-\mu r}\right) .
\end{gathered}
$$

(3) Ruin probability model of the railway business

Based on the Ohori and Morichi (2016) ${ }^{2}$ application of the Cramér-Lundberg model ${ }^{15)-22)}$, the surplus 
process of the railway business, denoted by $\left\{U_{t} ; t \geq\right.$ $0\}$, is described as follows:

$$
U_{t}:=u_{0}+P_{t}-S_{t}
$$

where

$u_{0}$ : the initial reserves of the railway business at the beginning of a fixed time interval $[0, t](t \geq 0), u_{0}$ $\geq 0$ (e.g., internal reserves, fund balance, etc.),

$P_{t}$ : the additional procurable funds within a fixed time interval $[0, t]$ in the railway business (e.g., insurance money, subsidy, etc.),

$S_{t}$ : the aggregate loss caused by natural disasters that occur in a fixed time interval $[0, t]$ in the railway business.

Because there is a difference in the disaster characteristics of every railway business, $P_{t}$ corresponds one-to-one with its $E\left(S_{t}\right)$ and $\theta$ as follows:

$$
\begin{aligned}
c & :=(1+\theta) E(S) \\
P_{t} & :=c t=(1+\theta) E(S) t
\end{aligned}
$$

where

$c$ : additional procurable funds within a time unit of typically one year in the railway business,

$\theta$ : the safety loading factor of additional procurable funds for an expected aggregate loss in the railway business, $\theta \geq 0$.

Thus, $U_{t}$ is described as follows:

$$
U_{t}=u_{0}+(1+\theta) E(S) t-S_{t} .
$$

We are now interested in the probability of ruin due to natural disaster. Focusing on $u_{0}$ and $\theta$, which are the main factors of RF, the ruin probability in the railway business, denoted by $\varepsilon\left(u_{0}, \theta\right)$, is written as follows:

$$
\varepsilon\left(u_{0}, \theta\right):=P\left(U_{t}<0\right)=P\left[u_{0}+(1+\theta) E(S) t-S<0\right] .
$$

\section{(4) Lundberg's inequality}

We define ruin as a state of $U_{t}<0$ in formula (11), and we define the random variable $T$ in formula (16) below, which expresses the ruin time:

$$
T:=\min \left\{t \mid U_{t}<0\right\} .
$$

Using ruin time $T$, the ruin probability $\varepsilon$ can also be expressed in formula (17) as follows:

$$
\varepsilon=P(T<\infty) \text {. }
$$

The ruin probability defined in formula (15) is obtained by applying the Cramér-Lundberg model. Formula (18) is established under the assumption in

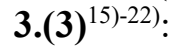

$$
P\left(U_{t}<0\right)=\frac{\exp \left(-R u_{0}\right)}{E\left[\exp \left(-R U_{T}\right) \mid T<\infty\right]} .
$$

Here, $R$ on the right side of the formula (18) is called the adjustment coefficient, which is a unique, positive real number by which the stochastic process $\left\{\exp \left(-R U_{t}\right) ; t \geq 0\right\}$ becomes a martingale. In other words, $R$ is a unique positive real number that satisfies the following formula (19) for any real number $t$ :

$$
E\left[\exp \left(-R U_{t}\right) \mid U_{\tau}\right]=\exp \left(-R U_{\tau}\right) \quad(t \geq \tau) .
$$

This adjustment coefficient $R$ should satisfy the following equation $(20)^{15)-22)}$ :

$$
\lambda+c R=\lambda M_{X}(R) .
$$

If there is a positive real root that satisfies the equation (20) for the adjustment coefficient $R$ in the ruin probability model in which the aggregate loss process $\left\{S_{t} ; t \geq 0\right\}$ represents a compound Poisson process, unique determination is possible ${ }^{15)-22)}$. Based on the preceding proof ${ }^{15-22)}$, Lemma 1 below can also be proved under this mathematical condition, even in cases of storm and flooding disaster RF in the railway business:

Lemma 1: In the storm and flooding disaster RF defined in Sections 3.(1), 3.(2), 3.(3), and 3.(4), if there is a positive real root (the adjustment coefficient $R$ ) that satisfies the equation (20), unique determination is possible.

[Proof] Based on the formula

$$
g(r)=\lambda M_{X}(r)-\lambda-c r,
$$

a positive real root that satisfies the equation (20) is a positive real root that satisfies $g(r)=0$. In this case, the following formulas are established:

$$
\begin{gathered}
g(0)=0 \\
\frac{d}{d r} g(r)=\lambda \frac{d}{d r} M_{X}(r)-c .
\end{gathered}
$$

In the case of storm and flooding disaster RF in railway business, the following formula is established with attention paid to formulas (6) and (12):

$$
\left.\frac{d}{d r} g(r)\right|_{r=0}=\lambda M_{X}^{(1)}(0)-c=-\theta \lambda \mu<0 .
$$

In addition, as the following formula can be established for any $r>0, g(r)$ becomes concave up in the interval $(0, \infty)$ :

$$
\frac{d^{2}}{d r^{2}} g(r)=\lambda \frac{d^{2}}{d r^{2}} M_{X}(r)=\lambda E\left(X^{2} e^{r X}\right)>0 .
$$

Hence, if a minimum value of $g(r)$ exists from the formulas (22), (24), and (25), the positive real number $a$ exists in case that $g(r)$ becomes minimum when $r=a$ and $g(a)<0$ is satisfied. Also, for the positive real number $b$ and the probability $p$ that satisfy the formula

$$
P(X>b)=p>0,
$$

the following inequality is established:

$$
M_{X}(r) \geq \int_{b}^{\infty} e^{r x} f_{X}(x) d x \geq e^{r b} p .
$$

Then, the following formula can be obtained:

$$
\lim _{r \rightarrow \infty} g(r) \geq \lim _{r \rightarrow \infty}\left(\lambda e^{r b} p-\lambda-c r\right)=\infty .
$$

Accordingly, the solution of the equation (20) is 
uniquely determined in the interval $(a, \infty)$ if it exists other than the trivial solution $r=0$. Q.E.D.

Meanwhile, Theorem 1, which is called Lundberg's inequality based on the pioneering works achieved by Lundberg and Cramér, is generally established ${ }^{15)-22)}$. Theorem 1 plays a key role in this study and is shown below.

Theorem 1 (Lundberg's inequality): Suppose the initial reserves at the beginning of a fixed time interval are $u_{0}$ in the ruin probability model for natural disasters described in Section 3.(3) and the adjustment coefficient $R$ is the smallest positive solution to the equation (20) described in Section 3.(4). Then, the ruin probability $\varepsilon$ satisfies the following inequality:

$$
\varepsilon \leq \exp \left(-R u_{0}\right) \quad\left(u_{0} \geq 0\right) .
$$

[Proof] The proof of Theorem 1 under the mathematical condition of Section 3, is shown in APPENDIX A.

\section{(5) Inequality of ruin probability caused by storm} and flooding disasters in the railway business

If Lundberg's inequality in Theorem $\mathbf{1}$ is applied to storm and flooding disaster RF in the railway business to determine ruin probability $\varepsilon$, Proposition 1 can be derived:

Proposition 1: Suppose the initial reserves at the beginning of a fixed time interval are $u_{0}$ in the ruin probability model for storm and flooding disasters described in Sections 3.(1), 3.(2), 3.(3), and the adjustment coefficient $R$ is the unique positive solution to equation (20) described in Section 3.(4). Then the ruin probability $\varepsilon\left(u_{0}, \theta\right)$ defined as (15) satisfies the following inequality:

$$
\varepsilon\left(u_{0}, \theta\right) \leq \exp \left(-R u_{0}\right)
$$

where

$$
\begin{gathered}
\varepsilon\left(u_{0}, \theta\right)=\frac{1}{1+\theta} \exp \left(-R u_{0}\right) \quad(\theta \geq 0), \\
R=\frac{\theta}{(1+\theta) \mu} .
\end{gathered}
$$

[Proof] Based on Ohori and Morichi (2016) ${ }^{2}$, the equalities (31) and (32) are established for storm and flooding disaster RF in the railway business under the conditions in Sections 3.(1), 3.(2), 3.(3), and 3.(4). Moreover, inequality (30) is established in the special case that natural disasters are limited to storm and flooding events for Theorem 1. Q.E.D.

The ruin probability $\varepsilon\left(u_{0}, \theta\right)$ is referred to as " $\varepsilon$ " hereinafter.

(6) Equality of annual additional procurable funds for storm and flood disaster RF in the railway business

In the practical work in storm and flooding disaster
$\mathrm{RF}$ in the railway business, it is often difficult to increase initial reserves in a short period of time. Accordingly, a short-term, direct measure for stable corporate management during storm and flooding disasters ensures sufficient additional procurable funds, such as insurance. Proposition 1 represents the inequality in a conservative approximation of the ruin probability $\varepsilon$ using the adjustment coefficient $R$. It is convenient if the annual additional procurable fund $c$ can also be expressed by the adjustment coefficient $R$. The following Proposition 2 realizes this expression. Proposition 2: In storm and flooding disaster RF in the railway business defined in Sections 3.(1), 3.(2), 3.(3), and 3.(4), the annual additional procurable fund $c$ defined in the formula (12) is expressed as formula (33) below, which uses the adjustment coefficient $R$ :

$$
c=\frac{\lambda \mu}{1-\mu R} \quad\left(0<R<\frac{1}{\mu}\right) .
$$

[Proof] Equation (20) can be simplified for $c$ as follows:

$$
c=\frac{\lambda}{R}\left\{M_{X}(R)-1\right\} .
$$

In storm and flooding disaster RF in the railway business, $M x(R)$, which is expressed in formula (5), is substituted into formula (34) as follows:

$$
c=\frac{\lambda}{R}\left\{\frac{1}{1-\mu R}-1\right\}=\frac{\lambda \mu}{1-\mu R} .
$$

where the adjustment coefficient $R$ is a positive real number. From the domain in formula (5), the domain in formula (35) is as follows:

$$
0<R<\frac{1}{\mu} \text {. }
$$

Then the proof is completed. Q.E.D.

Moreover, because the adjustment coefficient $R$ for storm and flooding disaster RF in railway business can be expressed in the formula (32), the domain (36) of $R$ is established based on any $\theta \geq 0$. However, if the adjustment coefficient $R$ is approximated, attention should be paid to the domain (36) of $R$. Further explanation in this regard is provided in $\mathbf{4}$.

\section{APPROXIMATION TECHNIQUES}

\section{(1) Approximation theory}

From Propositions 1 and $\mathbf{2}$ described, ruin probability and additional procurable funds in storm and flooding disaster RF in railway business are determined by the adjustment coefficient $R$, taking disaster characteristics and initial reserves as givens. Accordingly, in the approximation of ruin probability and additional procurable fund, a central challenge is the approximation of adjustment coefficient. We attempt to approximate the adjustment coefficient based on 
Table 1 Approximation ideas for adjustment coefficient $R$.

\begin{tabular}{c|l|l}
\hline No & \multicolumn{1}{|c|}{ Approximation ideas } & \multicolumn{1}{c}{ Sections } \\
\hline \hline 1 & $\begin{array}{l}\text { Approximation based on } \\
\text { Proposition 1 }\end{array}$ & $\begin{array}{l}\text { 3.(5), 3.(6), } \\
\text { 4.(2) }\end{array}$ \\
\hline 2 & $\begin{array}{l}\text { Approximation by } \\
\text { the Maclaurin expansion }\end{array}$ & 3.(6), 4.(3) \\
\hline 3 & $\begin{array}{l}\text { Asymptotic approximation based } \\
\text { on the Newton-Raphson method }\end{array}$ & $\begin{array}{l}\text { 3.(5), 3.(6), } \\
\text { 4.(4) }\end{array}$ \\
\hline
\end{tabular}

the three ideas shown in Table 1, with reference to the previous studies reviewed in Section 2.(3).

The mathematical approximation formulas for ruin probability and additional procurable funds are derived using the approximation formulas for each adjustment coefficient obtained based on the ideas shown in Table 1. The three technical requirements (i.e., conservativeness, approximate accuracy, and domain) described in Section 2.(3) are considered. In Section 4.(5), we comprehensively summarize the approximate techniques obtained in Section 4.

\section{(2) Approximation derived from Proposition 1}

If the right side of the inequality (30) is as follows:

$$
\varepsilon_{0}:=\exp \left(-R u_{0}\right),
$$

$\varepsilon_{0}$ is a conservative approximation of the ruin probability $\varepsilon$ in Proposition 1. Furthermore, the following Proposition 3 is established from Propositions 1 and 2.

Proposition 3: In storm and flooding disaster RF in railway businesses defined in Sections 3.(1), 3.(2), 3.(3), and 3.(4), the following is established with $R_{1}$ defined in formula (38):

$$
\begin{gathered}
R_{1}:=\frac{-\log \varepsilon}{u_{0}} \\
R \leq R_{1} \\
c \leq \frac{\lambda \mu}{1-\mu R_{1}} \quad\left(0<R_{1}<\frac{1}{\mu}\right) .
\end{gathered}
$$

If the right side of the inequality (40) is as follows:

$$
c_{1}:=\frac{\lambda \mu}{1-\mu R_{1}}=\frac{\lambda \mu u_{0}}{u_{0}+\mu \log \varepsilon},
$$

then inequality (40) can be rewritten as follows:

$$
c<c_{1} \quad\left(\exp \left(-\frac{u_{0}}{\mu}\right)<\varepsilon \leq 1\right) .
$$

Inequality (40) can also be rewritten with the safety loading factor $\theta$ in additional procurable funds as follows:

$$
\begin{gathered}
\theta_{1}:=\frac{-\mu \log \varepsilon}{u_{0}+\mu \log \varepsilon} \\
0 \leq \theta \leq \theta_{1} \quad\left(\exp \left(-\frac{u_{0}}{\mu}\right)<\varepsilon \leq 1\right) .
\end{gathered}
$$

[Proof] First, the inequality (30) in Proposition 1 is transformed for $R$ as follows:

$$
R \leq \frac{-\log \varepsilon}{u_{0}} .
$$

Inequality (39) is established if the right side of inequality (45) is put as $R_{1}$, as in formula (38).

Second, for the annual additional procurable fund $c$ defined in formula (12), inequality (40) is established based on $\lambda \geq 0, \mu>0$, formula (33), and inequality (39).

Third, if formula (38) is substituted into the domain of $R_{1}$ in inequality (40), the following inequality is established:

$$
0<\frac{-\log \varepsilon}{u_{0}}<\frac{1}{\mu} .
$$

Then, the ruin probability $\varepsilon$ can be simplified as follows:

$$
\exp \left(-\frac{u_{0}}{\mu}\right)<\varepsilon \leq 1 .
$$

Accordingly, if $c_{1}$ is placed on the right side of inequality (40) as in formula (41), inequality (42) is established.

Finally, formulas (12) and (38) are substituted into inequality (40), and the following inequality is established:

$$
(1+\theta) \lambda \mu \leq \frac{\lambda \mu}{1-\mu\left(\frac{-\log \varepsilon}{u_{0}}\right)} .
$$

Then inequality (48) is simplified for $\theta \geq 0$ as follows:

$$
0 \leq \theta \leq \frac{-\mu \log \varepsilon}{u_{0}+\mu \log \varepsilon} .
$$

Accordingly, if $\theta_{1}$ is placed on the right side of inequality (49) as in formula (43), inequality (44) is established. Q.E.D.

As suggested by Proposition 3, $c_{1}$ can be used as the conservative approximation value of the additional procurable fund $c$, and $\theta_{1}$ can be used as the conservative approximation value of the safety loading factor $\theta$ in additional procurable funds for storm and flooding disaster RF. In conducting such approximation calculations, attention should be paid to the domains of inequalities (42) and (44). Specifically, in practical $\mathrm{RF}$, if the initial reserve $u_{0}$ is 0 or near 0 or if $u_{0} / \mu$ is near 0 as the expectation value $\mu$ of the number of losses is much larger compared to $u_{0}$, it is expressed as follows:

$$
\frac{u_{0}}{\mu} \rightarrow 0 \Rightarrow \exp \left(-\frac{u_{0}}{\mu}\right) \rightarrow 1 .
$$

It should be noted that the interval lengths of the domains of inequalities (42) and (44) are close to 0 . In this regard, specific examples are shown as evaluation in $\mathbf{5}$. 
Moreover, since $0<R \leq R_{1}$ is obtained from the inequality (39), inequality

$$
\exp \left(-R u_{0}\right)>\exp \left(-R_{1} u_{0}\right)
$$

is established for $u_{0} \geq 0$. Therefore, the right side of inequality (51) is not appropriate as a conservative approximation of the ruin probability based on inequality (30) in Proposition 1.

\section{(3) Approximation by the Maclaurin expansion}

The Maclaurin expansion of the moment-generating function $M_{X}(R)$ of the random variable $X$ is expressed by the following formula:

$$
M_{X}(R)=E\left(e^{R X}\right)=\sum_{k=0}^{\infty} \frac{R^{k}}{k !} E\left(X^{k}\right) .
$$

If formula (52) is substituted into equation (20), the following formula is established:

$$
c=\frac{\lambda}{R} \sum_{k=1}^{\infty} \frac{R^{k}}{k !} E\left(X^{k}\right)=\lambda \sum_{k=1}^{\infty} \frac{R^{k-1}}{k !} E\left(X^{k}\right) .
$$

Now, regarding the storm and flooding disaster RF in the railway business described in Section 3.(2), if formula (7) is substituted into formula (53), the following formula is obtained:

$$
c=\lambda \mu \sum_{k=1}^{\infty}(\mu R)^{k-1} \quad\left(0<R<\frac{1}{\mu}\right) .
$$

a) Approximation formulas by Maclaurin expansion up to the quadratic term

In formulas (8) and (12), if the Maclaurin expansion up to the quadratic term $(k=2)$ is used in formula (54), the following formula is obtained:

$$
c=(1+\theta) \lambda \mu>\lambda \mu+\lambda \mu^{2} R .
$$

Then it is simplified for $R>0$ as shown below:

$$
0<R<\frac{\theta}{\mu} \text {. }
$$

Here, it is placed as follows:

$$
R_{2}:=\frac{\theta}{\mu} \text {. }
$$

As is $0<R<R_{2}$ for $u_{0} \geq 0$, inequality is established:

$$
\exp \left(-R u_{0}\right)>\exp \left(-R_{2} u_{0}\right) \text {. }
$$

Therefore, the right side of inequality (58) is not appropriate as a conservative approximation of the ruin probability based on inequality (30) in Proposition 1.

However, inequality

$$
c=\frac{\lambda \mu}{1-\mu R}<\frac{\lambda \mu}{1-\mu R_{2}} \quad\left(0<R_{2}<\frac{1}{\mu}\right)
$$

is established based on $\lambda \geq 0, \mu>0$ and Proposition 2. As the right side of inequality (59) can be obtained as a conservative approximation value of the additional procurable fund $c$ by the Maclaurin expansion up to the quadratic term, it is expressed as follows:

$$
c_{2}:=\frac{\lambda \mu}{1-\mu R_{2}}=\frac{\lambda \mu}{1-\theta} .
$$

Here, if formula (57) is substituted into the domain of $R_{2}$ in inequality (59), it is simplified for $\theta \geq 0$ as shown below:

$$
0 \leq \theta<1 .
$$

Then inequality (59) can be rewritten as follows:

$$
c<c_{2} \quad(0 \leq \theta<1) \text {. }
$$

b) Approximation formulas by the Maclaurin expansion up to the cubic term

As is the case in a) of 4.(3), the Maclaurin expansion up to the cubic term $(k=3)$ in formula (54) generates the following formula:

$$
c=(1+\theta) \lambda \mu>\lambda \mu+\lambda \mu^{2} R+\lambda \mu^{3} R^{2} .
$$

Then inequality

$$
\mu^{2} R^{2}+\mu R-\theta<0
$$

is established. As the adjustment coefficient $R$ is a positive real number, the following inequality is established:

$$
0<R<\frac{-1+\sqrt{1+4 \theta}}{2 \mu} .
$$

Here, it is expressed as follows:

$$
R_{3}:=\frac{-1+\sqrt{1+4 \theta}}{2 \mu} .
$$

As $0<R<R_{3}$ for $u_{0} \geq 0$, inequality

$$
\exp \left(-R u_{0}\right)>\exp \left(-R_{3} u_{0}\right)
$$

is established. Therefore, the right side of inequality (67) is not appropriate as a conservative approximation of the ruin probability based on inequality (30) in Proposition 1.

However, inequality

$$
c=\frac{\lambda \mu}{1-\mu R}<\frac{\lambda \mu}{1-\mu R_{3}} \quad\left(0<R_{3}<\frac{1}{\mu}\right)
$$

is established based on $\lambda \geq 0, \mu>0$ and Proposition 2. As the right side of the inequality (68) can be obtained as the conservative approximation value of the additional procurable fund $c$ by the Maclaurin expansion up to the cubic term, it is expressed as follows:

$$
c_{3}:=\frac{\lambda \mu}{1-\mu R_{3}}=\frac{2 \lambda \mu}{3-\sqrt{1+4 \theta}} .
$$

Here, if formula (66) is substituted into the domain of $R_{3}$ in inequality (68), it is simplified as $\theta \geq 0$ as shown below:

$$
0 \leq \theta<2 .
$$

Then inequality (70) can be rewritten as follows:

$$
c<c_{3} \quad(0 \leq \theta<2) \text {. }
$$


(4) Asymptotic approximation by the NewtonRaphson method

In 3.(4), Lemma 1 provides that a unique determination is possible if there is a positive real root that satisfies equation (20) in storm and flooding disaster $\mathrm{RF}$ in the railway business. Here, we describe an asymptotic approximation method using the NewtonRaphson method for the adjustment coefficient $R$, which is a real root.

The asymptotic approximation of the adjustment coefficient $R$ by the Newton-Raphson method is expressed as $R_{4}$. By using $R_{4}$, the following formula is obtained:

$$
\varepsilon_{4}:=\exp \left(-R_{4} u_{0}\right) .
$$

In so doing, the following formula is established in the domain of $\varepsilon_{4}$ for the random variable $\varepsilon$ in Proposition 1:

$$
\varepsilon \leq \exp \left(-R_{4} u_{0}\right)=\varepsilon_{4} .
$$

Moreover, the conservative approximation value of traditional procurable fund $c$ using $R_{4}$ is expressed as follows:

$$
c_{4}:=\frac{\lambda \mu}{1-\mu R_{4}} .
$$

Thus, $c_{4}$ approximation is near the additional procurable fund $c$ in its domain in Proposition 2. The following relation is established:

$$
c \approx c_{4} .
$$

In a) and b) of Section 4.(4) below, the two cases are described in which the initial value $r_{0}$ of recursion formula is regarded as $R_{2}$ and $R_{3}$ in Section 3.(3), respectively.

\section{a) Approximation formula if the initial value is $R_{2}$}

Proposition 4: If there is a positive real root that satisfies equation (20) in storm and flooding disaster RF in the railway business as defined in Sections 3.(1), 3.(2), 3.(3), and 3.(4), an approximation solution of the recursion formula composed of formulas (76) and (77) is expressed as $R_{4}$. Then the adjustment coefficient $R$ is determined as the asymptotic approximation solution $R_{4}$.

$$
\begin{gathered}
r_{0}=R_{2}=\frac{\theta}{\mu} \quad(0 \leq \theta<1) \\
r_{n+1}=r_{n}-\frac{g\left(r_{n}\right)}{g^{\prime}\left(r_{n}\right)} \quad\left(\begin{array}{c}
n=0,1,2, \cdots \\
0 \leq \theta<1
\end{array}\right)
\end{gathered}
$$

where

$$
g(r)=\frac{\lambda}{1-\mu r}-\lambda-(1+\theta) \lambda \mu r .
$$

[Proof] As indicated in Lemma 1, a unique determination is possible if there is a positive root in equation (20) for the adjustment coefficient $R$, and the function $g(r)$ indicated in equation (21) satisfies the convergence conditions of the Newton-Raphson method.
Thus, in consideration of the progression $\{r n ; n=0$, $1,2, \ldots\}$, which satisfies the recursion formula (77), the value of the adjustment coefficient $R$, which is a positive real root satisfying $g(r)=0$, can be approximately determined. Formula (76) is obtained using $R_{2}$ as the initial value $r_{0}$, which is the approximation formula (57) for the adjustment coefficient $R$ described in a) of Section 3.(3).

In storm and flooding disaster RF in the railway business, $M_{X}(R)$ can be expressed as in formula (5). If $M_{X}(R)$ is substituted into formula (21), the function $g(r)$ is indicated as shown in formula (78). Q.E.D.

b) Approximation formula if the initial value is $R_{3}$

Proposition 5: If there is a positive real root that satisfies equation (20) in storm and flooding disaster RF in the railway business, as defined in Sections 3.(1), 3.(2), 3.(3), and 3.(4), an approximation solution of the recursion formula, which is composed of formulas (79) and (80), is expressed as $R_{3}$. Then the adjustment coefficient $R$ is determined as an asymptotic approximate solution $R_{4}$.

$$
\begin{aligned}
& r_{0}=R_{3}=\frac{-1+\sqrt{1+4 \theta}}{2 \mu} \quad(0 \leq \theta<2) \\
& r_{n+1}=r_{n}-\frac{g\left(r_{n}\right)}{g^{\prime}\left(r_{n}\right)} \quad\left(\begin{array}{c}
n=0,1,2, \cdots \\
0 \leq \theta<2
\end{array}\right)
\end{aligned}
$$

where $g(r)$ is the same as in formula (78).

[Proof] Formula (80) is obtained by using $R_{3}$, which is the approximation formula (66) for the adjustment coefficient $R$ described in $\mathbf{b})$ of Section 3.(3), as the initial value $r_{0}$ in the recursion formula in the proof of Proposition 4. The proof of Proposition 4 is applicable to other aspects. Q.E.D.

\section{(5) Summary of approximation techniques}

Regarding Sections 4.(2), 4.(3), and 4.(4), Table 2 comprehensively summarizes the approximate theoretical formulas based on Table 1. If these approximation formulas were used in practical work for RF, the domain that ensures conservativeness as well as approximate accuracy would also be clarified. Accordingly, in Section 5, the evaluation of the theoretical formulas shown in Table 2 is conducted by focusing on the domain and the approximation accuracy from a practical viewpoint. 
Table 2 Theoretical formulas for conservative approximations of ruin probability and additional procurable funds in storm and flood disaster RF in the railway business.

\begin{tabular}{|c|c|c|}
\hline $\begin{array}{c}\text { Adjustment } \\
\text { coefficients and } \\
\text { approximation } \\
\text { formulas, domains } \\
\end{array}$ & \begin{tabular}{|c|} 
Ruin \\
probability and \\
approxima- \\
tion formulas \\
\end{tabular} & $\begin{array}{l}\text { Additional procurable } \\
\text { funds and } \\
\text { approximation formulas }\end{array}$ \\
\hline $\begin{array}{c}R=\frac{\theta}{(1+\theta) \mu} \\
0 \leq \theta\end{array}$ & $\begin{array}{c}\varepsilon_{0} \\
=\exp \left(-R u_{0}\right)\end{array}$ & - \\
\hline $\begin{array}{c}R_{1}=\frac{-\log \varepsilon}{u_{0}} \\
0 \leq \theta \leq \theta_{1}\end{array}$ & - & $c_{1}=\frac{\lambda \mu}{1-\mu R_{1}}=\frac{\lambda \mu u_{0}}{u_{0}+\mu \log \varepsilon}$ \\
\hline $\begin{array}{c}R_{2}=\frac{\theta}{\mu} \\
0 \leq \theta<1\end{array}$ & - & $c_{2}=\frac{\lambda \mu}{1-\mu R_{2}}=\frac{\lambda \mu}{1-\theta}$ \\
\hline $\begin{array}{c}R_{3}=\frac{-1+\sqrt{1+4 \theta}}{2 \mu} \\
0 \leq \theta<2\end{array}$ & - & $c_{3}=\frac{\lambda \mu}{1-\mu R_{3}}=\frac{2 \lambda \mu}{3-\sqrt{1+4 \theta}}$ \\
\hline $\begin{array}{c}R_{4} \quad\left(r_{0}=R_{2}\right) \\
0 \leq \theta<1 \\
R_{4} \quad\left(r_{0}=R_{3}\right) \\
0 \leq \theta<2\end{array}$ & $\begin{array}{c}\mathcal{E}_{4} \\
=\exp \left(-R_{4} u_{0}\right)\end{array}$ & $c_{4}=\frac{\lambda \mu}{1-\mu R_{4}}$ \\
\hline
\end{tabular}

[Legend] - : Not applicable, $\theta_{1}$ is described as the formula (43).

\section{EVALUATION OF APPROXIMATION TECHNIQUES}

\section{(1) Railway companies analyzed}

In order to evaluate the methodology proposed in Sections 3 and 4, approximation techniques (Table 2) are conducted using the data collected on the thirdsector railway companies shown in Fig. 2. The data reflect the actual losses caused by storm and flooding disasters, as well as financial data over the past 22 years from FY1991 to FY2013. These data were provided by the Third-Sector Railway Companies Association $^{23)}$ and the Railway Bureau of the Ministry of Land, Infrastructure, Transport and Tourism (MLIT).

First, the main reasons for analyzing the actual data of the third-sector railways are as follows:

1) The third-sector railway companies are distributed nationally (Fig. 2), and they are suitable for investigating the nationwide tendencies to storm and flooding disasters, including diverse factors, such as climate and topography.

2) Because almost none of the anti-disaster measure construction is performed in the third-sector railway companies, a population characteristic that affects damage outbreaks is kept as a condit ion equivalent to age $\mathrm{e}^{\text {Note (1) }}$.

3) Most third-sector railway companies have contin uous natural disaster insurance on civil engineer ng structures23). Therefore, historical data on

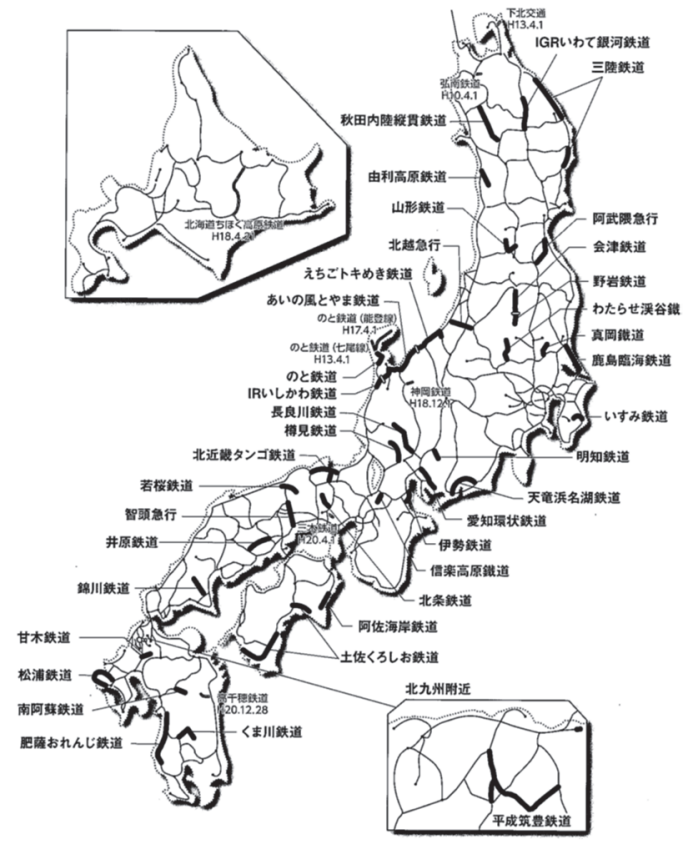

Fig.2 Locations of third-sector railway companies in Japan ${ }^{23)}$.

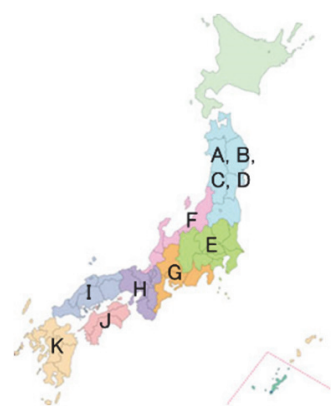

Fig.3 The 11 railway companies selected for the analysis.

disasters, such as insurance payments, are recorded exactly.

4) All actual data on public financial support in the subsidy system for restoration to railway companies are recorded by the MLIT.

5) The importance of storm and flooding disaster RF is increasing for railway businesses in financial difficulty, especially third-sector railways.

Second, we selected 11 railway companies for the analysis, which are shown in Fig. 3. The reasons for this selection include long-term data accumulation, retention of nationwide diversity in terms of landforms and climate conditions, easy understanding of disaster characteristics due to the availability of large amounts of data on the actual damage by storm and flooding disasters, and the differences in the financial conditions of the respective railway companies.

As described in Section 3.(2), the disaster characteristics of the annual aggregate loss caused by storm and flooding disasters in the railway business are expressed by two parameters $\lambda$ and $\mu$. As shown in Figs. 4 and 5, 11 companies of $\lambda$ and $\mu$ reflect nationwide 


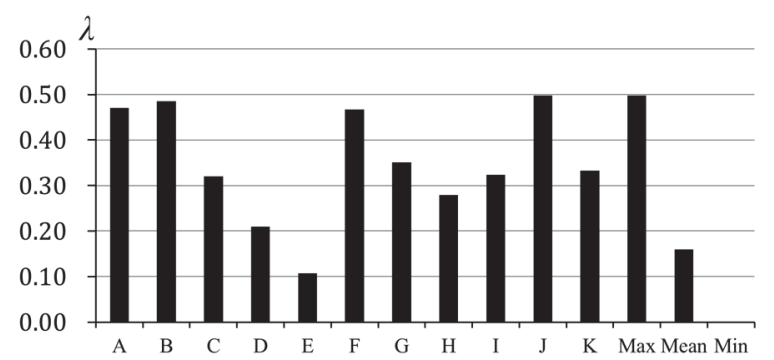

Fig.4 $\lambda$ of the 11 railway companies (FY1991-2013).

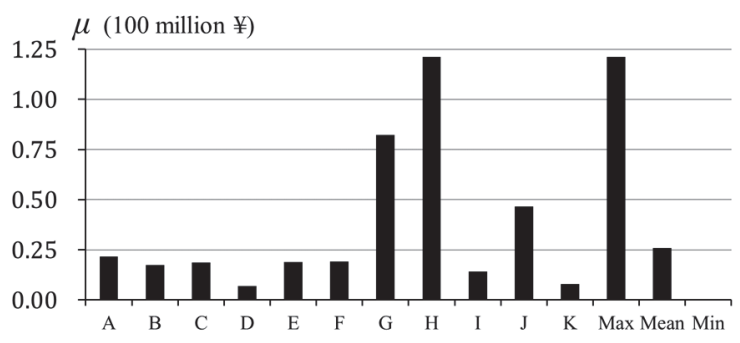

Fig.5 $\mu$ of the 11 railway companies (FY1991-2013).

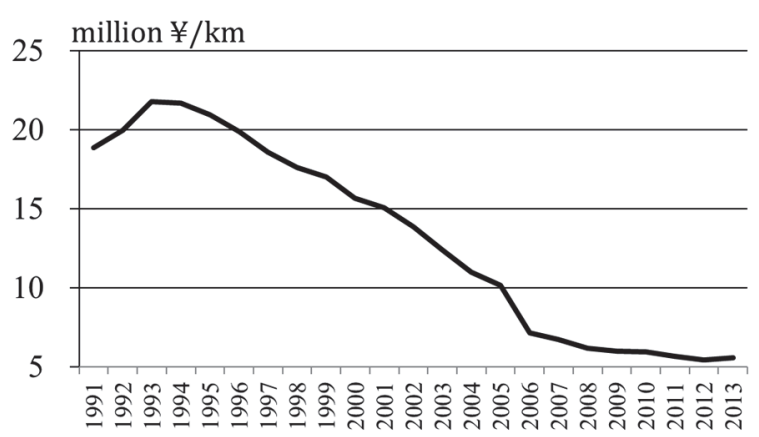

Fig.6 National average of initial reserves (FY1991-2013).

variations, respectively. Here, in the case were railway companies with $\lambda$ and $\mu$ are close to zero, both additional procurable funds and ruin probabilities are also close to zero. For this reason, these data were unsuitable for use in the evaluation data and were therefore excluded.

Third, the difference in the initial reserves is to be noticed on the financing situation. There are two features in the initial reserves of third-sector railways: one is the nationwide declining trend (Fig. 6), and the other is the large difference between each company (Fig. 7). The initial reserves $u_{0}$ of 11 companies reflect the smallest to largest variations nationwide, as shown in Fig. 8.

Fourth, the difference in the ruin probability was also considered in the sampling. Figure 9 shows that the calculated values of the ruin probability in FY2013 in storm and flooding disaster RF for the 11 railway companies based on the calculation proposed by Ohori and Morichi $(2016)^{2}$. The values of the ruin probability of companies $\mathrm{A}, \mathrm{F}$, and $\mathrm{H}$ are extremely

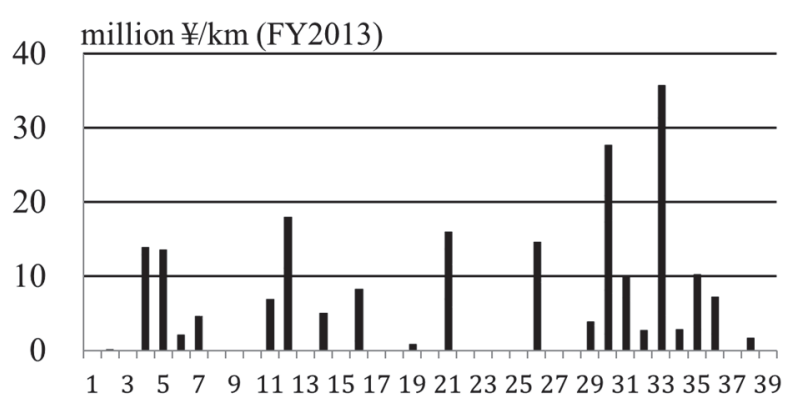

Fig.7 Initial reserves of third-sector railway companies.

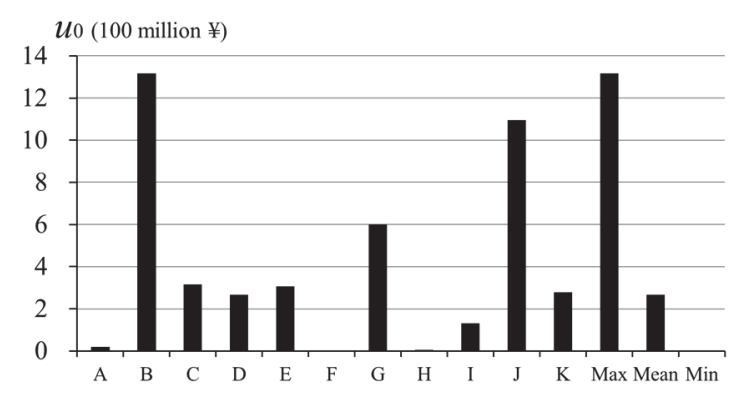

Fig.8 $u_{0}$ of 11 railway companies (FY2013).

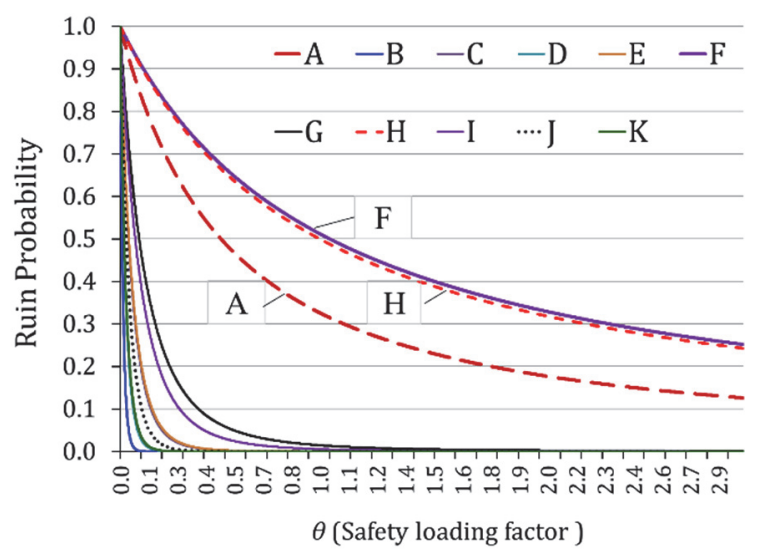

Fig.9 Ruin probability of the 11 railway companies (FY2013).

high, and the values of the other eight companies are generally $\theta \geq 0.5$, which means that their ruin probability is 0.1 or lower. A major reason seems to be the fact that the initial reserves $u_{0}$ of companies A, F, and $\mathrm{H}$ are 0 or near 0 , which is shown by the theoretical formulas (31) and (32) on ruin probability.

Fifth, Fig. 10 shows the distribution of $u_{0}$ and $1 / \mu$ among the 11 railway companies, which are the factors of the domain and the approximation accuracy of $\varepsilon_{0}$ and $c_{1}$, as described in Section 4.(2). The fact that the ruin probability becomes smaller as $u_{0} / \mu$ becomes larger is attributable to the theoretical formulas (31) and (32). In other words, as $u_{0}$ and $1 / \mu$ become larger, the ruin probability becomes smaller. Figure 11 shows the values of $u_{0} / \mu$ of the 11 railway companies. The comparison of Figs. 9 and $\mathbf{1 1}$ indicates that the values of the ruin probability of companies $\mathrm{A}, \mathrm{F}$, and 


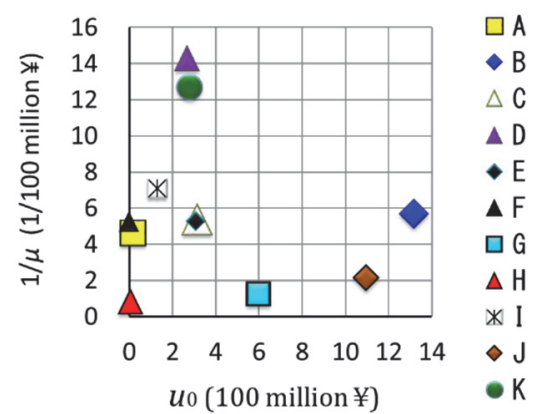

Fig.10 $u_{0}$ and $\mu$ of the 11 railway companies (FY2013).

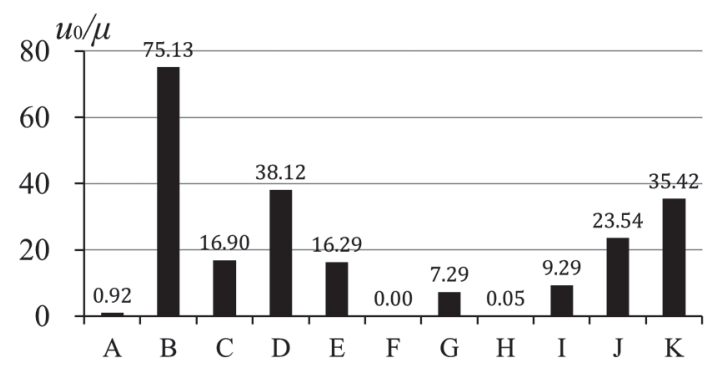

Fig.11 $u_{0} / \mu$ of the 11 railway companies (FY2013).

$\mathrm{H}$ with a small $u_{0} / \mu$ value are extremely high, as shown in Fig. 9. The conclusion is that as a result of the evaluation of the 11 railway companies, the domains and approximate accuracy of $\varepsilon_{0}$ and $c_{1}$ are found to be dependent on $u_{0} / \mu$. Then based on the difference in $u_{0} / \mu$ in the 11 companies and the different combinations of their initial reserves $u_{0}$ and disaster characteristics $1 / \mu$, the results of the evaluation of the companies A, B, G, H, J, and $\mathrm{K}$ are presented below. The values of $u_{0} / \mu$ in the six companies are indicated in the order of $\mathrm{H}<\mathrm{A}<\mathrm{G}<\mathrm{J}<\mathrm{K}<\mathrm{B}$, as shown in Fig. 11. In addition, the combinations of $u_{0}$ and $1 / \mu$ are quite different.

\section{(2) Evaluation concerning approximation of ad- justment coefficient}

We describe the results of the evaluation concerning approximation of adjustment coefficients in the left columns of Table 2.

a) Evaluation concerning $R_{4}$

First, we describe the results of the evaluation of the asymptotic approximation $R_{4}$ based on the Newton-Raphson method. Figure 12 shows the example of company A, and the other railway companies show almost the same trend as that depicted in Fig. 12. In other words, the following two points were found to be a general trend in the number of calculations to convergence:

1) When $\theta$ is near 0 , convergence occurs at approximately $n=2$.

2) As $\theta$ approaches the upper limit of the domain, the number of calculations increases. However,
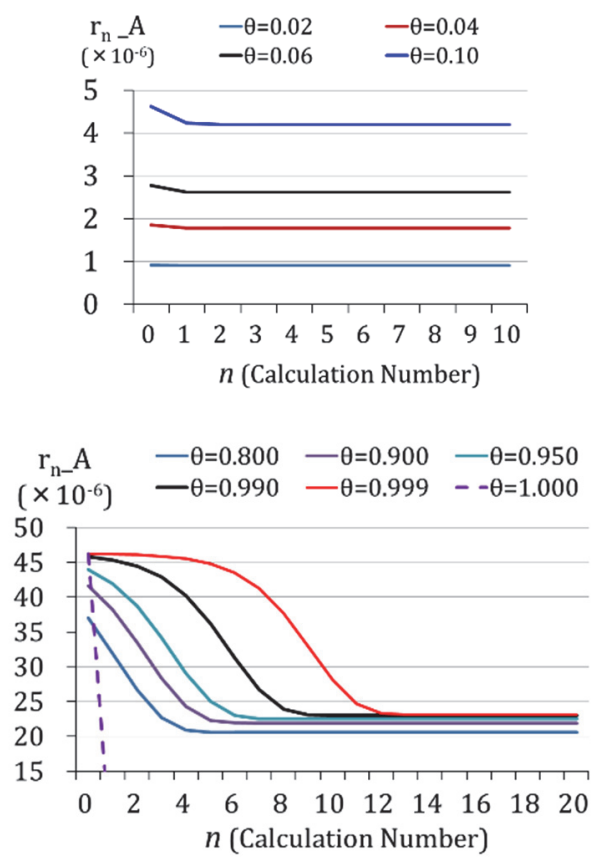

Fig.12 Asymptotic approximation of adjustment coefficient using the Newton-Raphson method (A, $r_{0}=R_{2}$, FY2013).

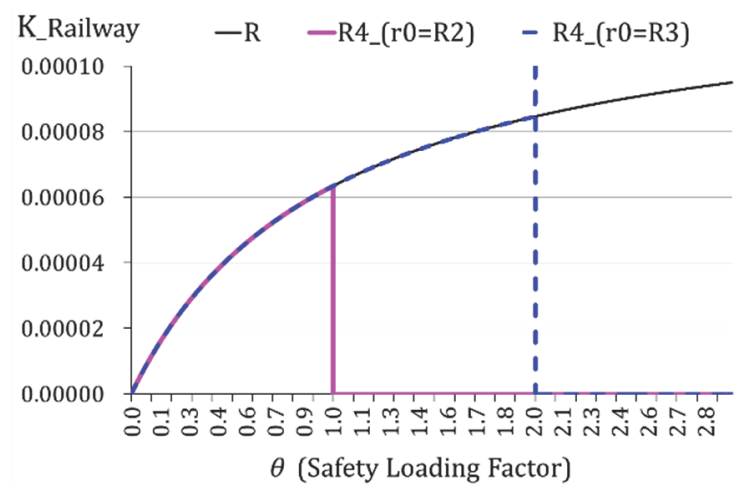

Fig.13 Comparison of initial values of $R_{4}(\mathrm{~K}, n=20$, FY2013).

convergence occurs at $n=12 \sim 14$.

The following are the results of the analysis in which $R_{4}$ was compared with the initial values $r_{0}=$ $R_{2}$ and $r_{0}=R_{3}$. The example of company $\mathrm{K}$ is shown as Fig. 13, and the other companies showed as an almost equal trend (Fig. 13). In other words, the following two points are understood as a general trend.

1) When the initial value is $R_{2}, R_{4}$ converges to almost the true value of $\mathrm{R}$ in the domain $0 \leq \theta<1$.

2) When the initial value is $R_{3}, R_{4}$ converges to almost the true value of $R$ in the domain $0 \leq \theta<2$.

b) Evaluation concerning approximation of adjustment coefficient

Figure 14 shows the results of the evaluation of the adjustment coefficients and the respective approximation values of companies $\mathrm{A}, \mathrm{B}, \mathrm{G}, \mathrm{H}, \mathrm{J}$, and $\mathrm{K}$. Because the values of $u_{0} / \mu$ are shown in the order of companies $\mathrm{H}<\mathrm{A}<\mathrm{G}<\mathrm{J}<\mathrm{K}<\mathrm{B}$, the same order is used in Fig. 14. 

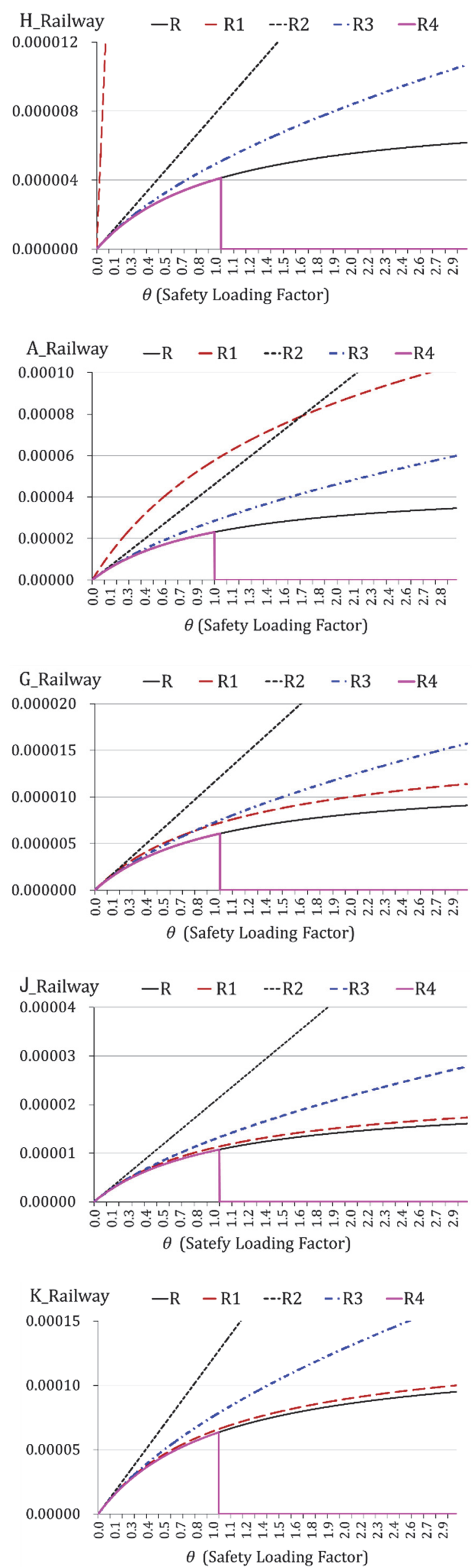

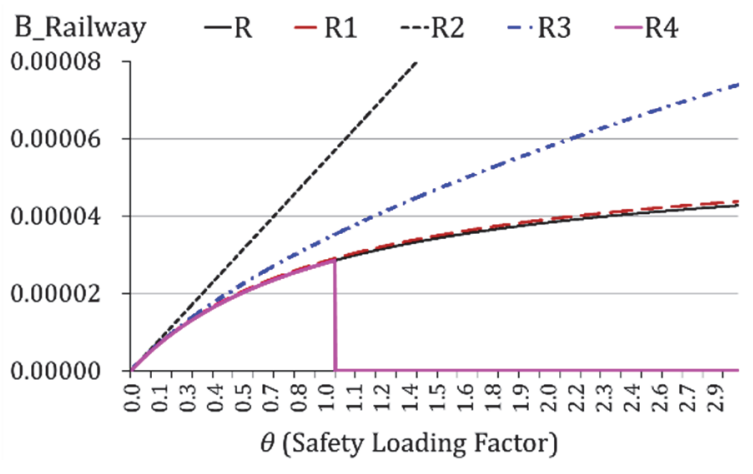

Fig.14 Adjustment coefficient and approximations (FY2013).

As shown in Fig. 14, the asymptotic approximation $R_{4}$ by the Newton-Raphson method is obtained when $r_{0}=R_{2}$ and $n=20$ in a) of Section 4.(4). The domain and approximation accuracy of $R_{4}$ are the same as described in a) of Section 5.(2) above. In the approximation by the Maclaurin expansion, the relationship of $R<R_{3}<R_{2}$ is established because the approximation accuracy is theoretically higher as the number of expansion terms increases. The results of the evaluation are the same as those shown in Fig. 14, and they agreed with the theory. For example, as shown in Fig. 14, as $R_{2}$ linearly increases against $\theta$, the approximate accuracy of $R_{3}$ is higher than that of $R_{2}$ if the value of $\theta$ increases. Since $R_{2}$ is calculated by formula (57), and $R_{3}$ is calculated by formula (66) in Fig. 14, it is somewhat difficult to grasp, but the domain of $R_{2}$ is $0 \leq \theta<1$, and the domain of $R_{3}$ is 0 $\leq \theta<2$ according to the convergence conditions described in Section 4.(3). These domains are clarified by considering the result of the evaluation of $c_{2}$ or $c_{3}$ as noted in Section 5.(5) below.

The approximate accuracy of $R_{1}$ based on Proposition 1 is high because it is close to the true value of $R$ in companies $\mathrm{B}, \mathrm{J}$, and $\mathrm{K}$ where $u_{0} / \mu \geq 23.54$. The approximation accuracy of $R_{1}$ is also high in the company $\mathrm{G}$ where $u_{0} / \mu=7.29$ compared to that of $R_{3}$. However, the approximation accuracy is low in companies $\mathrm{A}$ and $\mathrm{H}$ where $u_{0} / \mu<1$. A possible reason is that the domains of $R_{1}$ and $\theta$ are dependent on $1 / \mu$ and $u_{0} / \mu$, respectively, as described in Section 4.(2). Moreover, the interval length of the domain approaches 0 when the values of $1 / \mu$ and $u_{0} / \mu$ are near 0 . Further explanations of these results are provided in Section 5.(3).

As described above, the results of the evaluation of the approximation of the adjustment coefficient showed $R \approx R_{4}<R_{3}<R_{2}$ in the domains indicated in Table 2. These results support the theory that $R_{1}$ is dependent on the value of $u_{0} / \mu$. 


\section{(3) Evaluation of approximation based on Propo- sition 1}

Section 5.(2) describes the results of the evaluation of the approximation accuracy and the domain of $R_{1}$ based on Proposition 1. The domain of $R_{1}$ was rewritten using $\theta$ as shown in inequality (44), and $\theta_{1}$, which is defined in formula (43), serves as the upper limit of the domain. Figure 15 shows the results of the evaluation of $\theta_{1}$ in companies $\mathrm{A}, \mathrm{B}, \mathrm{G}, \mathrm{H}, \mathrm{J}$, and K.

As described in Section 4.(2), Fig. 15 shows that the interval length of the domain approaches 0 when the domain of $R_{1}$ is dependent on the value of $u_{0} / \mu$, and the value of $u_{0} / \mu$ is near 0 . For example, as the values of $u_{0} / \mu$ in companies $\mathrm{A}$ and $\mathrm{H}$ are near 0 , the interval length of the domain of $\theta$ is near 0 . Moreover, $\theta_{1}$ in company A diverges when $\theta>0.714$, and it agrees with the theoretical domain (44) of $\theta$ shown in Proposition 3.

We also consider that $\theta_{1}$ is a conservative approximation of $\theta$ in inequality (44). As shown in Fig. 15, the differences between $\theta_{1}$ and $\theta$ are small in companies $\mathrm{B}, \mathrm{J}$, and $\mathrm{K}$ where $u_{0} / \mu \geq 23.54$. The primary reason is that the approximation accuracy of $R_{1}$ in companies $\mathrm{B}, \mathrm{J}$, and $\mathrm{K}$, where $u_{0} / \mu \geq 23.54$, is high as described in b) of Section 5.(2).

Section 5.(4) describes the ruin probability $\varepsilon_{1}$ based on Proposition 1, and Section 5.(5) describes the additional fund $c_{1}$.

\section{(4) Evaluation concerning the conservative ap- proximation of ruin probability}

In formula (37) and (72), $\varepsilon_{0}$ and $\varepsilon_{4}$, respectively, is proposed for the conservative approximation of the ruin probability $\varepsilon$. The values of $u_{0} / \mu$ are in the order of $\mathrm{H}<\mathrm{A}<\mathrm{G}<\mathrm{J}<\mathrm{K}<\mathrm{B}$. However, Fig. 16 shows the results of the evaluations of $\varepsilon, \varepsilon_{4}$, and $\varepsilon_{0}$ in the order of $\mathrm{H}, \mathrm{A}, \mathrm{G}$, and $\mathrm{J}$, which is the ascending order of their $u_{0} / \mu$ values. Here, $\varepsilon_{4}$ is the value of $R_{4}$ determined when $r_{0}=R_{2}$ and $n=20$ in a) of Section 4.(4).

As shown in Fig. 16, the following two points are understood concerning the domain:

1) The domain of $\varepsilon_{0}$ is $\theta \geq 0$.

2) The domain of $\varepsilon_{4}\left(r_{0}\right.$ (initial value of $\left.\left.R_{4}\right)=R_{2}\right)$ is 0 $\leq \theta<1$, and divergence occurs when $\theta \geq 1$. These results agree with the theory described in a) of Section 4.(4). Moreover, if $r_{0}$ (initial value of $R_{4}$ ) $=R_{3}$, the domain of $\varepsilon_{4}$ is $0 \leq \theta<2$, which aligns with the theory described in b) of Section 4 .(4).

As shown in Fig. 16, the following four points are understood concerning approximation accuracy:

1) As the value of $u_{0} / \mu$ becomes larger, the approximate accuracy of $\varepsilon_{0}$ and $\varepsilon_{4}$ becomes higher.

2) The approximation accuracy of $\varepsilon_{0}$ and $\varepsilon_{4}$ becomes lower in companies $\mathrm{H}$ and $\mathrm{A}$, which are close to $0<u_{0} / \mu<1$ and 0 . Particularly, in company $\mathrm{H}$,

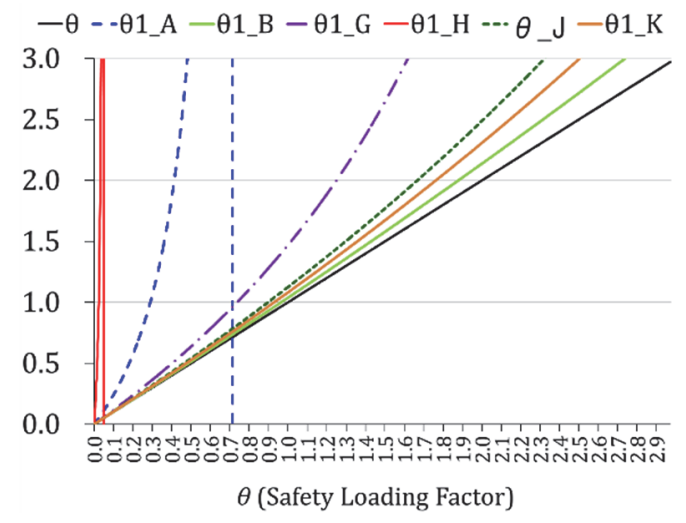

Fig.15 Safety loading factor and approximations (FY2013).

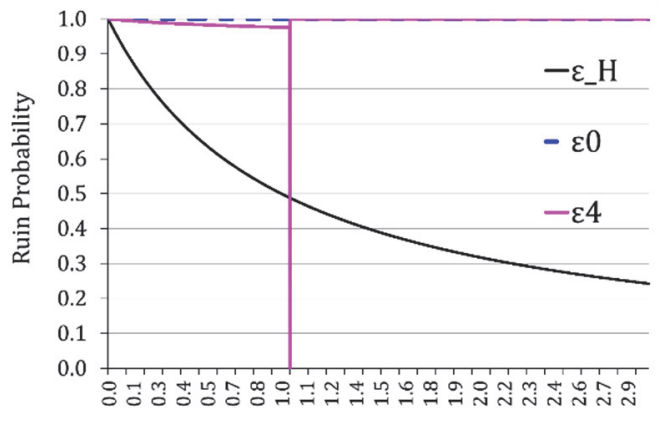

$\theta$ (Safety Loading Factor)
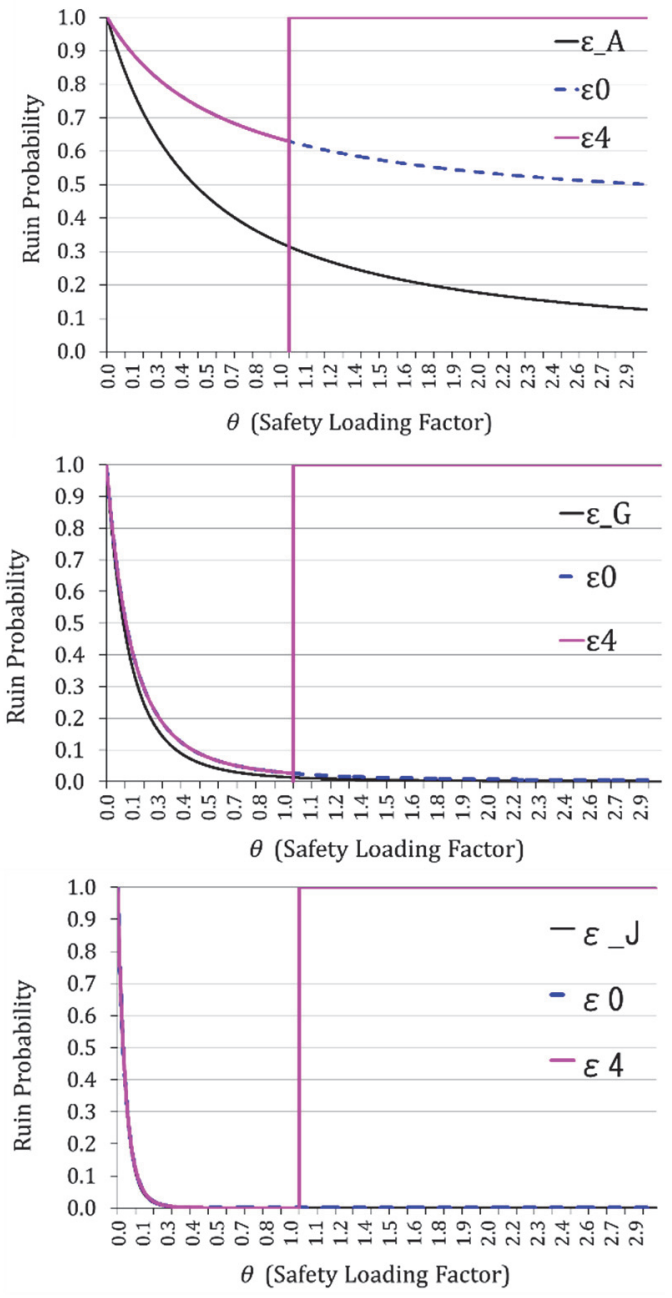

Fig.16 Ruin probability and approximations (FY2013). 
where $u_{0} / \mu=0.05$ (almost 0 ), $\varepsilon_{0}$ is almost 1 for any $\theta$, and the approximation accuracy of $\varepsilon$ is very low.

3) In companies $\mathrm{G}, \mathrm{J}, \mathrm{K}$, and $\mathrm{B}$, where $u_{0} / \mu \geq 7.29$, the approximation accuracy of $\varepsilon_{0}$ and $\varepsilon_{4}$ is high. In companies $\mathrm{J}, \mathrm{K}$, and $\mathrm{B}$, where $u_{0} / \mu \geq 23.54$, the approximate accuracy of $\varepsilon_{0}$ and $\varepsilon_{4}$ almost agrees with that of $\varepsilon$ for any $\theta$.

4) The approximate accuracy of $\varepsilon_{4}$ is also dependent on the value of $u_{0} / \mu$.

\section{(5) Evaluation of the conservative approximation of additional procurable fund}

In formula (41), (60), (69), and (74), $c_{1}, c_{2}, c_{3}$, and $c_{4}$ are proposed as the conservative approximations of the additional procurable fund $c$. The values of $u_{0} / \mu$ are shown in the order of $\mathrm{H}<\mathrm{A}<\mathrm{G}<\mathrm{J}<\mathrm{K}<$ B. However, Fig. 17 shows the results of the evaluations of $c, c_{1}, c_{2}, c_{3}$, and $c_{4}$, which are arranged in the order of $\mathrm{H}, \mathrm{A}, \mathrm{G}, \mathrm{J}, \mathrm{K}$, and $\mathrm{B}$, which is the ascending order of their $u_{0} / \mu$ values. Here, $\varepsilon_{4}$ is the value of $R_{4}$ determined when $r_{0}=R_{2}$ and $n=20$ in a) of Section 4.(4).

As shown in Fig. 17, the following four points are understood concerning the domain:

1) The domain of $c_{1}$ is theoretically $0 \leq \theta \leq \theta_{1}$, which was confirmed. Because $\theta_{1}$ is dependent on the value of $u_{0} / \mu$, the interval length of the domain approaches 0 when the value of $u_{0} / \mu$ is near 0 , and the domain becomes larger as the value of $u_{0} / \mu$ becomes larger. The range of $\theta$ in which $c_{1}$ of companies $\mathrm{A}$ and $\mathrm{H}$ diverges supports the theoretical domain (44) of $\theta$ shown in Proposition 3.

2) The domain of $c_{2}$ is theoretically $0 \leq \theta<1$ in inequality (61). As shown in Fig. 17, $c_{2}$ diverges when $\theta \geq 1$. Thus, the results of the evaluation support the theory.

3) The domain of $c_{3}$ is theoretically $0 \leq \theta<2$ in inequality (70). As shown in Fig. 17, $c_{2}$ diverges when $\theta \geq 2$. Thus, the results of the evaluation support the theory.

4) The domain of $c_{4}\left(r_{0}=R_{2}\right)$ is theoretically $0 \leq \theta$ $<1$ as described in Proposition 4. As shown in Fig. 17, $c_{4}$ diverges when $\theta \geq 1$, and the theory agrees with the results of the evaluation. Moreover, if $r_{0}=R_{3}$, the domain of $\varepsilon_{4}$ is $0 \leq \theta<2$, and it agrees with $0 \leq \theta<2$ described in Proposition 5.

As shown in Fig. 17, the following four points are understood concerning the approximation accuracy of $c_{1}, c_{2}, c_{3}$, and $c_{4}$ :

1) Regarding the approximation accuracy of $c_{1}$, the approximation accuracy of $\varepsilon_{0}$ and $\varepsilon_{4}$ become higher as the value of $u_{0} / \mu$ becomes larger. The reason is that $R_{1}$ and $\theta_{1}$ are dependent on the value of $u_{0} / \mu$ as described in b) of Section 5.(2) and
5.(3). Based on the results of the evaluation shown in Fig. 17, the approximation accuracy of $c_{1}$ in companies $\mathrm{J}, \mathrm{K}$, and $\mathrm{B}$, where $u_{0} / \mu \geq 23.54$, is allowable as an estimated value in practical work. Moreover, in company B, where $u_{0} / \mu \geq 75.13$, the approximation accuracy of $c_{1}$ is excellent.

2) The approximation accuracy of $c_{2}$ is dependent on that of $R_{2}$ in formula (60). $R_{2}$ sharply rises if $\theta$ ranges from 0.6 to 1 in formula (57). The domain $0 \leq \theta<1$ above diverges when $\theta \geq 1$. Hence, a possible range for the practical approximation of $c_{2}$ is $0 \leq \theta<0.6$.

3) The approximation accuracy of $c_{3}$ is dependent on that of $R_{3}$ in formula (69). $R_{3}$ sharply rises if $\theta$ ranges from 1.3 to 2 in formula (66), and the domain $0 \leq \theta<2$ above diverges when $\theta \geq 2$. Hence, a possible range for the practical approximation of $c_{3}$ is $0 \leq \theta<1.3$.

4) The approximation accuracy of $c_{4}\left(r_{0}=R_{2}\right)$ almost converges to $c$ in the domain $0 \leq \theta<1$. The reason is that $R_{4}$ almost converges to $\mathrm{R}$ in the domain as described in a) of Section 5.(2). In comparing $R_{2}$ and $R_{3}$ as $r_{0}$ (the initial value of $R_{4}$ ), their approximation accuracy is almost the same in the domain. However, $c_{4}\left(r_{0}\right.$ is the initial value of $\left.R_{4},\right)=$ $R_{3}$ ) may be more convenient because the domain of $R_{3}$ is $0 \leq \theta<2$.

\section{(6) Practical implications}

In Section 5, the technical requirements were evaluated for the theoretical approximation formulas presented in Section 4. The evaluations were based on actual data collected from railway companies across Japan. The convenience of the formulas was evaluated. Based on the results, Table 3 summarizes the domains that provide approximation accuracy, which could be used in practical applications.

The degrees of approximation accuracy are shown in the lowest line in Table 3. The approximation accuracy of the asymptotic approximation $R_{4}$ is the highest. In the approximation by the Maclaurin expansion, the approximation accuracy increased as the number of expansion terms increased. Therefore, the approximation based on $R_{3}$ instead of $R_{2}$ is more accurate. Although the approximation based on Proposition 1 is easier to understand intuitively, $R_{1}, \theta_{1}$, and $c_{1}$ change in accordance with the value of $u_{0} / \mu$ as described in Sections 4.(2), 5.(2), 5.(3), and 5.(5). Accordingly, in practical applications, attention should be paid when a certain degree of approximation accuracy is required. The values of the domain of $u_{0} / \mu$ described in Table 3 are the results based on evaluations of theoretical values. They represent a possible domain for the practical application of approximation theory. In Table 3, the right-hand columns show the 

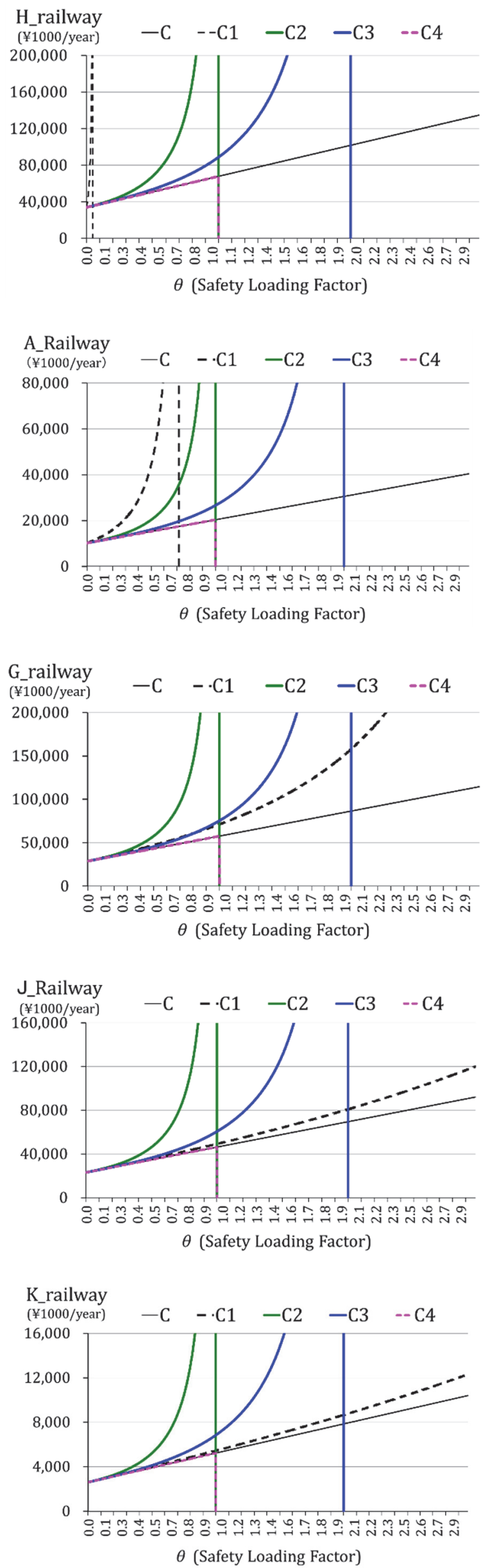

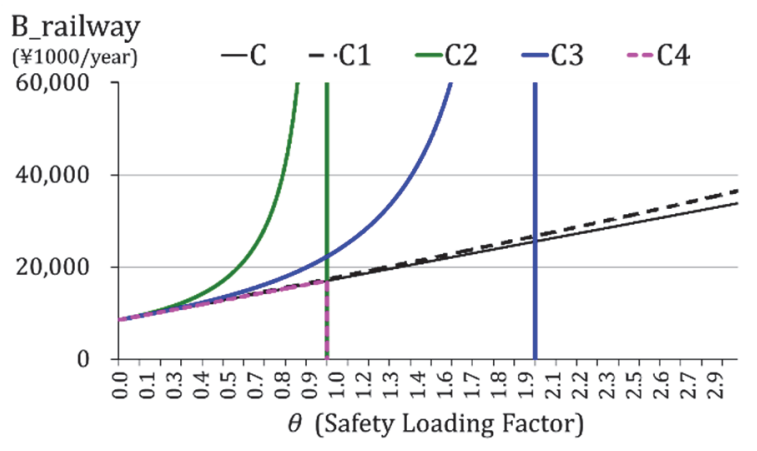

Fig.17 Additional procurable funds and approximations (FY2013).

comprehensive evaluations of the domain, approximation accuracy, and so on, according to convenience. The symbol $\bigcirc$ represents a recommended approximation technique in the domain. It is desirable to use the calculation load, approximation accuracy, domain, and so on, depending on the users' needs.

\section{CONCLUSION}

\section{(1) Main results}

The main results of this study are that for the first time, the approximation techniques for determining ruin probability and additional procurable funds that contribute to storm and flooding disaster RF in the railway business were derived from both mathematical theory and evaluations. Table 3 summarizes simplified calculation methods that meet the technical requirements for approximation. Based on Table 3, for example, the approximate value of additional procurable funds can easily be calculated using $c_{3}$ in the practical domain $0 \leq \theta<1.3$ in roughly estimating the maximum insurance payment in the following year. In another example, the approximate value of additional procurable funds can easily be calculated using $c_{1}$ from the target value $\varepsilon$ of ruin probability if $u_{0} / \mu \geq$ 23 in estimating the maximum insurance payment in the following year. As noted above, in practical work on RF, to examine the maximum insurance payment of hundreds of millions of yen, an approximate value can be easily obtained, which reduces the calculation workload and meets the technical requirements of practical work in RF.

The specific outcomes of this study are divided into academic contributions and practical contributions:

\section{a) Academic contributions}

1) Inequality (30), which serves as the theoretical basis for conducting a conservative approximation of ruin probability in storm and flooding disaster $\mathrm{RF}$, is presented mathematically as Proposition 1. 
In addition, Proposition 1 plays a key role in conservatively approximating ruin probability.

2) In Section 3.(6), additional procurable funds are expressed mathematically using an adjustment coefficient in storm and flooding disaster RF. In addition, Proposition 2 plays a key mathematical role in the conservative approximation of additional procurable funds.

3) The approximate values, $\theta_{1}$ and $c_{1}$, which were mathematically derived from Proposition 3, changed depending on $u_{0} / \mu$.

4) The approximation formulas $\left(\varepsilon_{0}, \varepsilon_{4}\right)$ and the domains of ruin probability for storm and flooding disaster RF are derived mathematically, and they are systematically summarized in Table 2 .

5) The conservative approximation formulas $\left(c_{1}, c_{2}\right.$, $\left.c_{3}, c_{4}\right)$ and the domains of additional procurable funds for storm and flooding disaster RF are derived mathematically, and they are summarized in

\section{Table 2.}

b) Practical contributions

1) In Section 5.(4), an evaluation was conducted to show that the accuracy of the approximation $\varepsilon_{0}$ of ruin probability proposed in Section 4.(2) changes depending on $u_{0} / \mu$ in the practical domain. Specifically, the findings showed that when the value of $u_{0} / \mu$ was near 0 (i.e., $\mathrm{H}$ railway and A railway), the approximation accuracy was very low. In contrast, when the value of $u_{0} / \mu$ was 7 or higher (i.e., G railway and $\mathrm{J}$ railway), the approximation accuracy was high.

2) In Sections 5.(2), 5.(3), and 5.(5), the findings showed that the domains and the approximation accuracy of $R_{1}, \theta_{1}$ and $c_{1}$ proposed in Section 4.(2) changed depending on $u_{0} / \mu$. Therefore, the value of $u_{0} / \mu$ was 23 (J railway) or higher to obtain a practical approximation accuracy.

3) In Section 5.(5), practical domains were evaluated taking into account that the approximation accuracy of the additional procurable fund approximation $\left(c_{2}, c_{3}\right)$, which was based on the Maclaurin expansion proposal in Section 4.(3), decreased near the upper limit of the domain.

4) In Section 5.(4), the findings showed that the ruin probability approximation $\varepsilon_{4}$ based on the New-

Table 3 Conservative approximation techniques for ruin probability and additional procurable funds on storm and flooding disasters RF in the railway business.

\begin{tabular}{|c|c|c|c|c|}
\hline $\begin{array}{l}\text { Adjustment coefficients and } \\
\text { approximation formulas }\end{array}$ & $\begin{array}{l}\text { Possible domains for } \\
\text { practical application }\end{array}$ & \begin{tabular}{|c|} 
Ruin probability and \\
approximation \\
formulas \\
\end{tabular} & \begin{tabular}{|c|} 
Additional procurable \\
funds and approximation \\
formulas
\end{tabular} & Evaluation of convenience \\
\hline $\begin{array}{l}R: \text { Adjustment coefficient } \\
\qquad R=\frac{\theta}{(1+\theta) \mu}\end{array}$ & $\begin{array}{c}\frac{u_{0}}{\mu} \geq \text { about } \quad 7 * \\
0 \leq \theta\end{array}$ & $\begin{array}{c}\varepsilon: \text { Ruin probability } \\
\varepsilon=\frac{1}{1+\theta} \exp \left(-R u_{0}\right) \\
\varepsilon_{0}=\exp \left(-R u_{0}\right) \\
\end{array}$ & $\begin{array}{l}c: \text { Additional procurable } \\
\quad \text { funds } \\
c=(1+\theta) \lambda \mu=\frac{\lambda \mu}{1-\mu R}\end{array}$ & $\begin{array}{l}\text { The approximation accuracy of } \varepsilon \\
0 \text { and } \varepsilon 4 \text { is almost the same, but } \\
\text { the domain of } \varepsilon 0 \text { is wider than } \\
\text { that of } \varepsilon 4 .\end{array}$ \\
\hline $\begin{array}{c}R_{1: \text { Approximation based on }} \\
\text { Proposition } 1 \\
R_{1}=\frac{-\log \varepsilon}{u_{0}}\end{array}$ & $\mid \begin{array}{c}\frac{u_{0}}{\mu} \geq \text { about } 23 * \\
0 \leq \theta \leq \theta_{1}=\frac{-\mu \log \varepsilon}{u_{0}+\mu \log \varepsilon}\end{array}$ & & $c_{1}=\frac{\lambda \mu}{1-\mu R_{1}}=\frac{\lambda \mu u_{0}}{u_{0}+\mu \log \varepsilon}$ & $\begin{array}{l}\times \text { ) When } u 0 / \mu \text { is near } 0 \text {, } \\
\theta 1 \text { is near } 0 \text { and } c 1 \text { diverges. } \\
\text { O) When } u 0 / \mu \geqq \text { about } 23 \text {, } \\
\text { the approximation accuracy } \\
\text { of } \theta 1 \text { and } c 1 \text { is high. }\end{array}$ \\
\hline $\begin{array}{l}R^{2} \text { : Approximation by the } \\
\text { Maclaurin expansion up to } \\
\text { quadratic term } \\
\qquad R_{2}=\frac{\theta}{\mu}\end{array}$ & $0 \leq \theta<0.6^{*}$ & & $c_{2}=\frac{\lambda \mu}{1-\mu R_{2}}=\frac{\lambda \mu}{1-\theta}$ & \multirow{2}{*}{$\begin{array}{l}\text { The domain of } \theta \text { is larger for } R 3 \\
\text { and } C 3 \text { than } R 2 \text { and } C 2 \text {, and it } \\
\text { is more convenient as the } \\
\text { approximation accuracy of } R 3 \\
\text { and } C 3 \text { is higher. }\end{array}$} \\
\hline $\begin{array}{l}\text { OR 3: Approximation by the } \\
\text { Maclaurin expansion up to cubic } \\
\text { term } \\
\qquad R_{3}=\frac{-1+\sqrt{1+4 \theta}}{2 \mu} \\
\end{array}$ & $0 \leq \theta<1.3 *$ & & $c_{3}=\frac{\lambda \mu}{1-\mu R_{3}}=\frac{2 \lambda \mu}{3-\sqrt{1+4 \theta}}$ & \\
\hline $\begin{array}{l}R 4 \text { : Asymptotic approximation } \\
\text { based on the Newton-Raphson } \\
\text { method (Initial value }=R^{2} \text { ) } \\
\end{array}$ & $0 \leq \theta<1$ & \multirow{2}{*}{$\varepsilon_{4}=\exp \left(-R_{4} u_{0}\right)$} & \multirow{2}{*}{$c_{4}=\frac{\lambda \mu}{1-\mu R_{4}}$} & \multirow{2}{*}{$\begin{array}{l}\text { As the domain of } \theta \text { is larger for } \\
R 4 \text { (initial value }=R 3 \text { ), it is more } \\
\text { convenient. The approximation } \\
\text { accuracy is almost the same in } \\
\text { the domain. }\end{array}$} \\
\hline $\begin{array}{l}\mathrm{O} R^{4} \text { : Asymptotic approximation } \\
\text { based on the Newton-Raphson } \\
\text { method (Initial value }=R^{3} \text { ) }\end{array}$ & $0 \leq \theta<2$ & & & \\
\hline$R \approx R_{4}<R_{3}<R_{2}$ & Domain mentioned above & $\varepsilon \leq \varepsilon_{0} \approx \varepsilon_{4}$ & $c \approx c_{4}<c_{3}<c_{2}$ & $\begin{array}{l}\text { The relations are described in } \\
\text { left columns. }\end{array}$ \\
\hline
\end{tabular}


ton-Raphson method proposed in Section 4.(4) almost converges to $\varepsilon_{0}$ in the domain. However, the approximation accuracy changed depending on $u_{0} / \mu$ as in the case of $\varepsilon_{0}$. Furthermore, in Sections 5.(2) and 5.(4), the evaluation showed that in comparing $R_{2}$ and $R_{3}$ as $r_{0}$ (the initial value of $R_{4}$ ) when calculating $\varepsilon_{4}$, their approximation accuracies were almost the same. However, $R_{3}$ was more convenient because its domain was larger than that of $R_{2}$.

5) In Sections 5.(2) and 5.(4), the findings showed that the additional procurable fund approximation $c_{4}$ based on the Newton-Raphson method proposed in Section 4.(4) almost converged to the additional procurable fund $c$ in the domain. Additionally, in Sections 5.(2) and 5.(4), the findings showed that in comparing $R_{2}$ and $R_{3}$ as $r_{0}$ (the initial value of $R_{4}$ ) when calculating $c_{4}$, their approximation accuracies were almost the same. However, $R_{3}$ was more convenient because its domain was larger than that of $R_{2}$.

6) Table 3 provides a summary of the results of evaluating the technical requirements (i.e., conservativeness, approximation accuracy, and domain) for determining ruin probability $\left(\varepsilon_{0}, \varepsilon_{4}\right)$ and additional procurable funds $\left(c_{1}, c_{2}, c_{3}, c_{4}\right)$.

\section{(2) Further work}

This evaluation summarized as Table 3 was the result found in some limited cases. For further improvement, the following works should be done in the future.

First, it is desirable to refine the values of practical domains in Table 3 through evaluation in more cases after accumulating the actual data.

Second, it was found that the approximation accuracies of $\varepsilon_{0}$ and $\varepsilon_{4}$ both depend on the value of $u_{0} / \mu$. It is necessary to examine the practically allowable accuracy of the approximation in more cases after accumulating the actual data of $u_{0}, \mu$, and so on.

Third, the approximation accuracy of $c_{2}, c_{3}$ should be inspected for $\theta(0 \leq \theta<2)$ in more cases after accumulating the actual data.

Finally, it was found that the approximation accuracy and the practical domain of $c_{1}$ both depend on the value of $u_{0} / \mu$. It is also important to examine and evaluate the availability of $c_{1}$ as shown in Fig. 17 in more cases after accumulating the actual data of $u_{0}$, $\mu$, and so on.

ACKNOWLEDGMENT: The author is thankful for the support from the Japan Transport and Tourism Research Institute (JTTRI). I would like to express sincere gratitude to all concerned persons who supported this study, particularly the railway officials who cooperated in hearing investigations and data collection. I am very thankful to Dr. Tsunemi Watanabe for very helpful advice and discussions. I wish to thank the referees for giving useful comments. Finally, I am deeply grateful to Dr. Shigeru Morichi and Dr. Takashi Yanagawa for the encouragement they have given me.

Note (1) The author conducted 25 interview sessions with small- and medium-sized railway companies, third-sector railway companies, the Third-sector Railway Companies Association, Railway Bureau, non-life insurance companies, and risk engineering experts from 2014 to 2017.

\section{APPENDIX A PROOF OF THEOREM 1}

Regarding the martingale property of the stochastic process $\left\{\exp \left(-R U_{t}\right) ; t \geq 0\right\}$ defined in formula (18), the random variable $T$ expresses the ruin time for any $t \geq 0$ is $T \leq t, U_{T}<0 R>0$. Then the following formula is established:

$$
\begin{aligned}
E\left[\exp \left(-R U_{t}\right) \mid T \leq t\right] & =E\left[E\left\{\exp \left(-R U_{t}\right) \mid U_{T}\right\} \mid T \leq t\right] \\
& =E\left[\exp \left(-R U_{T}\right) \mid T \leq t\right]>1 .
\end{aligned}
$$

Thus, in the case of $\tau=0$ in formula (18), particularly the following formula for any $t \geq 0$ is obtained from formula (81):

$$
\begin{aligned}
& \exp \left(-R u_{0}\right)=E\left[\exp \left(-R U_{t}\right)\right] \\
& =E\left[\exp \left(-R U_{t}\right) \cap T \leq t\right]+E\left[\exp \left(-R U_{t}\right) \cap T>t\right] \\
& \geq E\left[\exp \left(-R U_{t}\right) \mid T \leq t\right] P(T \leq t) \geq P(T \leq t) .
\end{aligned}
$$

Because inequality (82) is established for any $t \geq 0$, inequality (29) is derived from the formula (17) if $t$ $\rightarrow \infty$ and the proof is completed. Q.E.D.

\section{REFERENCES}

1) Ohori, K. : A study on natural disaster risk finance in railway business; ruin probability and the application, Transport Policy Studies' Review, Vol. 18 (2), pp. 69-73, 2015. (in Japanese)

2) Ohori, K. and Morichi, S. : Ruin probability on natural disaster risk finance in the railway business, Journal of Japan Society of Civil Engineers. F4, Vol. 72, No. 2, pp. 63-72, 2016. (in Japanese)

3) Ohori, K. : A study on natural disaster risk finance: Historical review and fundamental analysis, Transport Policy Studies'Review, Vol. 19, No. 2, pp. 33-37, 2016. (in Japanese)

4) Uchida, S., Hirata, T., Matsuno, Y., Yoon, J. and Morichi, S. : Current status and issues of risk financing and role of public sector for post-disaster restoration of transportation facilities, Transport Policy Studies'Review, Vol. 12, No. 2, pp. 66-72, 2009. (in Japanese)

5) Morichi, S. : Institutional issues of infrastructure at risk, JSCE Magazine, Vol. 94, No. 8, pp. 38, 2009. (in Japanese)

6) Nozawa, K., Hirata, T., Sueyoshi, T. and Sasaki, S. : Risk management and role of public sector for post-disaster restoration of transportation facilities, Transport Policy Studies'Review, Vol. 13, No. 3, pp. 85-92, 2010. (in Japanese) 
7) Cabinet Office, Government of Japan: Disaster management in Japan, 2015.

8) Asian Development Bank (ADB): Operation for integrated disaster risk management 2014-2020, 2014.

9) Organization for Economic Co-operation and Development (OECD): Financial management of flood risk, OECD publishing, 2016.

10) Foot, K. A. (Ed.): The Financing of Catastrophe Risk, The University of Chicago Press, 1999.

11) Railway Technical Research Institute: Railways and Natural Disasters, Nikkan Kogyo Shinbun, 2015. (in Japanese)

12) Ohta, N. and Sugiyama, T. : Change in natural disasters and future disaster management in railways, The Journal of Japan Railway Civil Engineering Association, June 2009. (in Japanese)

13) Nakamura, T. and Ugata, T. : Seismic Risk Management, Gihodo Shuppan, 2009. (in Japanese)

14) East Japan Railway Company : Financial report for investors, March 2011. Retrieved from https://www.jreast.co.jp/ investor/guide/pdf/201103guide1.pdf (Accessed 7 March 2017) (in Japanese)

15) Lundberg, F. : Approximerad framställning av sannolike- hetsfunktionen, återförsäkering av kollektivrisker, Almqvist \& Wiksell, Uppsala, 1903.

16) Cramér, H. : On the mathematical theory of risk, Skandia Jubilee Volume, Stockholm, 1930.

17) Blom, G. : Harald Cramér 1893-1985, The Annals of Statistics, Vol. 15, No. 4. p. 1335, 1987.

18) Andersen, E. S. : On the collective theory of risk in case of contagion between the claims, Trans. XVth Int. Congress Actuaries, Vol. II, pp. 219-229, N.Y., 1957.

19) McNeil, A. J., Frey, R. and Embrechts, P. : Quantitative Risk Management: Concepts, Techniques and Tools, Princeton University Press, 2005.

20) Dickson, C. M. : Insurance Risk and Ruin, Cambridge University Press, 2005.

21) Stuart, A. K., Harry, H, P. and Gordon, E. W. : Loss Models from Data to Decisions, 3rd edition, Wiley, 2008.

22) Soren, A. and Hansjorg, A. : Ruin Probabilities, 2nd edition, World Scientific, 2010.

23) The Third-Sector Railway Companies Association: History of 30 Years, 2015. (in Japanese)

(Received August 31, 2017) 